\title{
El control de las empresas de seguros privados en la legislación nicaragüense. La protección del consumidor ${ }^{26}$
}

\author{
Elsy Marenco Corea \\ Labora en el Centro de Mediación y Arbitraje \\ lizethemarenco@hotmail.com
}

\begin{abstract}
Resumen
El tema que se desarrolla a continuación plantea la necesidad de fortalecer el marco legal existente en cuanto al control que ejerce el Estado en la actividad aseguradora en el país. Se presentan de forma general los principios básicos de seguros, lineamientos aplicados en toda Latinoamérica para la armonización y actualización del sistema de supervisión. Los ejes fundamentales sobre los que gira la supervisión de las empresas aseguradoras privadas en el país y se plantea la necesidad que existe en adoptar y modernizar el régimen jurídico de supervisión y regulación de las empresas aseguradoras, de cara a mejorar los mecanismos existentes para la protección al asegurado, sobre todo en el área de reclamos por pago de las indemnizaciones.
\end{abstract}

Palabras clave: seguros/ protección del consumidor/ SIBOIF/ supervisión

\begin{abstract}
The subject then develops a need to strengthen the existing legal framework regarding the control exercised by the State in the insurance business in the country. It provides an overview of the Insurance Core Principles, guidelines applied throughout Latin America for the harmonization and updating of the monitoring system. The fundamental axis on which turns the supervision of private insurance companies in the country. And there is a need exists to adopt and modernize the legal framework for supervision and regulation of insurance companies, in order to improve existing mechanisms to protect the insured, especially in the area of claims for payment of compensation.
\end{abstract}

Key words: insurance/ Consumer protection/ SIBOIF/ supervision

26 El presente artículo es el resultado del trabajo de investigación del I ciclo académico de la Maestría en Derecho de las Contrataciones; el cual además de ser evaluado por un Tribunal integrado por tres académicos; posteriormente, fue arbitrado por una Comisión a efectos de seleccionar a los participantes del II Encuentro de Investigación de Postgrado de la Universidad Centroamericana, Agosto 2010. 


\section{Introducción}

El mercado de seguros es un elemento clave en la industria financiera. Es importante no solo desde la perspectiva económica del país, también lo es desde un punto de vista social. La actividad aseguradora permite que las personas, ya sean naturales o jurídicas, puedan ceder sus riesgos a estas empresas, otorgándoles protección económica ante el eventual suceso del siniestro, lo que se traduce en bienestar económico para el país y para el asegurado o el beneficiario.

Tomando en cuenta lo anterior, los asegurados confían en que al suceder el siniestro la empresa aseguradora asuma el riesgo, para ello paga una prima a cambio de esta obligación. Por tal razón, la actividad aseguradora se basa en la confianza del público, que es un componente clave dentro de la industria y la insolvencia del asegurador puede afectar no solo a los particulares que confiaron en él sino a toda la economía nacional, de allí la necesidad de contar con un adecuado sistema de supervisión por parte del Estado que no solo otorgue beneficios a los asegurados, sino a las empresas aseguradoras, a la economía del país y a la población en general.

El propósito de este trabajo es el análisis del marco regulatorio que actualmente rige en el país para la supervisión de las aseguradoras, así como determinar si el mismo permite y da garantía para la protección de los derechos de los asegurados, y la sanidad financiera del mercado asegurador en el país.

La importancia del tema radica en la función económica que cumple la actividad aseguradora y el papel primordial que debe jugar el regulador de seguros para cumplir con su misión de contribuir al desarrollo económico del país mediante el logro de mercados de seguros confiables y eficientes, a través de una supervisión eficaz y regulación moderna, sin descuidar sus dos ejes primordiales, la protección del asegurado y de la economía nacional.

En Nicaragua no se han desarrollado estudios concretos sobre el papel y funciones del ente regulador de la actividad aseguradora, sin embargo encontramos de forma dispersa, algunos textos que tratan el tema. Por el contrario, encontramos muchos estudios monográficos que abordan de forma bastante detallada algunos ramos de seguros y la legislación 
vigente para éstos, en menor medida se encontraron textos que abordan lo relacionado al contrato de seguros. Todos ellos fueron tomados en cuenta para el desarrollo de esta investigación. Evidentemente existe un vacío sobre el análisis del tema, pero a nivel latinoamericano encontramos que países como Chile y México han emprendido un cambio significativo en el modelo de supervisión de la actividad aseguradora y actualmente debaten sobre el modelo de supervisión más adecuado, tomando en cuenta las particularidades de la actividad aseguradora y de sus mercados.

Con este estudio se pretende explicar el modelo de supervisión que actualmente están acogiendo varios países de la región y el cual Nicaragua acogerá en buena parte una vez esté aprobada la nueva Ley General de Instituciones de Seguros y Reaseguros, actualmente en la Asamblea Nacional. En ella se incluyen cada uno de los grandes lineamientos generales de la supervisión, haciendo énfasis en la protección al asegurado (consumidor) y los principios que rigen la actividad de supervisión. Esperamos que este trabajo pueda ser objeto de consulta para los diversos actores del proceso de supervisión. Es importante aclarar al lector, que no se entrará en el análisis del contrato de seguro y sus elementos, ya que se escapa al ámbito del estudio.

Las técnicas de investigación utilizadas fueron, la revisión bibliográfica de textos nacionales e internacionales, de ellos, principalmente los internacionales. El análisis documental se realizó de fuentes primarias y la entrevista, la cual se efectuó a funcionarios de la Superintendencia de Bancos y de Otras Instituciones Financieras (en adelante SIBOIF) y empresarios privados.

Finalmente el método implementado fue dogmático, el cual persigue como resultado final el desarrollo de investigaciones que conciben la problemática jurídica a la que se pretende brindar solución desde una perspectiva estrictamente formalista, quitando todo elemento fáctico en el tratamiento de la figura analizada.

Esta investigación se estructura en apartados básicos, el primero comprende los antecedentes de la actividad aseguradora privada y del marco regulatorio de dicha actividad. El segundo ahonda sobre los principios básicos de seguros (en adelante PBS). En el tercero se abordan el control de las empresas de seguros, su finalidad y los tipos de controles 
Revisla de Derecho

sobre los cuales la SIBOIF fiscaliza, y finalizamos con los actores claves en el proceso de supervisión.

\section{Antecedentes de la actividad aseguradora en Nicaragua}

Nicaragua a diferencia de otros países como México ${ }^{27}$ y Panamáa ${ }^{28}$, entre otros, inició la actividad aseguradora formalmente en el año 1940 con la creación de la primera empresa aseguradora privada, La Compañía Nacional de Seguros; su aparición obedeció, principalmente, a la inserción de la economía nicaragüense en el mercado mundial a través del café.

La organización y el impulso de la actividad aseguradora correspondieron inicialmente a empresarios extranjeros. Es así que a principios del siglo $\mathrm{XX}$ aparecen en el panorama nacional agentes y agencias de empresas extranjeras de seguros de vida: el Sol de Canadá, la Confederación del Canadá y la Manufacture Life de los Estados Unidos. (Habed Blandón, 2007).

Transcurridos 30 años de la presencia de empresas aseguradoras extranjeras, fue entre los años de 1939-1940 que se funda y organiza la primera aseguradora nicaragüense, La Compañía Nacional de Seguros, con capital privado y del Estado (la Escritura Social y los Estatutos de la Compañía Nacional de Seguros se publicaron en La Gaceta, Diario Oficial, correspondiente a los días 30 de Julio de 1940 y 10 de Agosto también de 1940). En los cuarenta años siguientes se crean seis compañías nacionales más de seguros, habiéndose liquidado una de ellas por quiebra: la Septentrional.

Según datos de la SIBOIF, al 19 de julio de 1979 operaban en Nicaragua doce compañías de seguros, seis nacionales y seis extranjeras:

Las empresas nacionales eran: 1) Compañía Nacional de Seguros de Nicaragua; 2) Compañía de Seguros la Protectora, S.A. 3) La Inmobiliaria

27 Que inició su actividad aseguradora en 1892 con la promulgación de la primera ley que rige a las compañías de seguros, mexicanas y extranjeras. Comisión Nacional para la Protección y Defensa de los Usuarios de Servicios Financieros. Origen de la actividad aseguradora en México. Recuperado el día 12 de abril de 2010, de http://www.condusef.gob.mx/index.php/item-3/794.html.

28 Que inició en la actividad aseguradora privada en 1910. Superintendencia de Seguros y Reaseguros de Panamá (Recuperado el día 21 de abril de 2010 http://www.superseguros.gob.pa/). 
de Seguros, S.A. 4) Compañía de Seguros la Occidental, S.A. 5) Compañía Nicaragüense de Seguros, S.A. 6) Compañía de Seguros la Capital, S.A.

Las empresas extranjeras eran: 1) Pan American Life Asurance Co. 2) Citizens Standard Life Insurance Co. 3) The American Home Insurance Co. 4) American Life Insurance Co. 5) British American Insurance Co. y 6) The Home Insurance Co.

Estas empresas tenían las siguientes características: eran privadas, competían entre sí por los negocios y su funcionamiento estaba regulado por la Superintendencia de Bancos. En 1978, las compañías de seguros extranjeras controlaban el $25.8 \%$ del mercado, mientras que las nacionales captaban el $74.2 \%$ de las primas totales netas; las filiales de empresas extranjeras eran especializadas en determinados tipos de seguros, a diferencia de las nacionales que atendían tanto seguros de vida como de daños. (SIBOIF, 2010).

En 1979, se crea El Instituto Nicaragüense de Seguros y Reaseguros (en adelante INISER), surge con el Decreto No. $107^{29}$, con el cual la Junta de Gobierno de Reconstrucción Nacional, nacionaliza la actividad aseguradora en Nicaragua. Esta institución nace con personería jurídica, patrimonio propio y capacidad legal para adquirir derechos y contraer obligaciones.

Se reservó para INISER el monopolio de asegurar y reasegurar en Nicaragua, constituyéndose así en sucesor, sin solución de continuidad, de todos los bienes muebles e inmuebles, derechos adquiridos y obligaciones contraídas por las empresas nacionales, que por dicho Decreto quedaron nacionalizadas.

Posteriormente este decreto fue modificado por los Decretos No. 321 y No. $1213^{30}$, y Reglamentado por el Consejo Directivo de INISER el o6 de septiembre de $1983^{31}$.

A las empresas extranjeras se les prohibió la venta de nuevos seguros, limitándolas a sostener sus obligaciones contraídas hasta su expiración.

29 Publicado en La Gaceta, Diario Oficial, No. 36 del día 20 de Octubre de 1979.

30 Publicados respectivamente en La Gaceta, Diario Oficial, No. 49 y No. 60 de fechas 27 de febrero de 1980 y 14 de marzo de 1983, respectivamente.

31 Publicado en La Gaceta, Diario Oficial, No. 229 del 07 de Octubre de 1983. 
En 1996 desaparece el monopolio de los seguros que tenía el Estado, ya que el art. 14 de la Ley de Reforma a Ley General de Instituciones de Seguros (Reforma de la LGIS), Ley No. 227, del 26 de julio de $1996^{32}$, este artículo de manera expresa deroga el art. 5 el Decreto 107 que reservaba exclusivamente al Estado la función de asegurador.

Según datos de la SIBOIF (2010), actualmente existen cinco compañías aseguradoras en Nicaragua legalmente establecidas para operar:

- Instituto Nicaragüense de Seguros Y Reaseguros - (INISER). Decreto No. 107. (1979).

- Metropolitana Compañía de Seguros S.A. - (METROSEG) Autorizada mediante la Resolución No. SIB-OIF-IV-28-96. (1996).

- Seguros América S.A. - (AMERICA) - Autorizada mediante la Resolución No. SIB-OIF-IV-29-96 (1996).

- Seguros Lafise, S.A. (SEGUROSSA) - Autorizada mediante la Resolución No. SIB-OIF-IV-30-96 (1996).

- Aseguradora Mundial S.A. (PACIFICO)- Autorizada mediante la Resolución No. SIB-OIF-V-15-97. (1997).

1. Antecedentes del marco regulatorio de la actividad aseguradora en Nicaragua

Las primeras regulaciones de la actividad aseguradora privada datan desde 1866, con la promulgación del Código Civil (C) que entró en vigencia el 25 de enero del año 1867. El Contrato de seguro privado estaba reglamentado en el Título XXXIII llamado "De los Contratos Aleatorios", ésta normativa únicamente remitía al Código de Comercio (Cc) vigente en esa época. Dicho cuerpo normativo era el que contenía la regulación de los seguros en general, ello obedece a que dicha actividad siempre se ha considerado de naturaleza mercantil y no civil.

El Código de Comercio de 1869 hizo una clara distinción entre los seguros terrestres y los seguros marítimos.

Posteriormente, el Código Civil de Nicaragua de 1904, en el Título XX "De los Contratos Aleatorios" del art. 3539 al art. 3606 regula el contrato de seguro privado haciendo énfasis en el contenido del contrato de seguro y las materias que pueden ser objeto de este contrato.

32 Publicado en La Gaceta, Diario Oficial, No. 150 del 12 de agosto de 1996. 
El Código de Comercio de 1917, regula actualmente lo relacionado al contrato de seguro en el país. Este contrato está normado en el Título XI, llamado "De los Contratos de Seguros", en los artículos 535 al 599 inclusive, y en los arts. 898 al 972 del Título "De los Contratos Especiales del Comercio Marítimo" por lo que hace a los seguros marítimos. Es importante hacer notar que desde la fecha de promulgación hasta hoy, el contrato de seguro no ha sido objeto de reformas sustanciales. Es por esta razón, que ha sido la costumbre mercantil la que ha dinamizado la actividad aseguradora en Nicaragua. En este título se sistematiza lo relacionado con:

- Definición del contrato de seguro.

- Se deja sentado el carácter mercantil de este contrato, independiente de la especie.

- Se establecen los requisitos de la póliza

- La nulidad del contrato de seguro

- Se clasifican los seguros en: Seguros contra daño (incendio, seguro de transporte terrestre); Seguro sobre la vida; otras clases de seguro, que según el Cc pueden ser objeto del contrato de seguro mercantil, cualquiera otra clase de riesgos que provenga de casos fortuitos o accidentes naturales y los pactos que se consignen deberán cumplirse, siempre que sean lícitos; y los seguros marítimos.

- Derechos y obligaciones de las partes.

En relación con la vigencia de las normas relacionadas al seguro en el Código Civil y las del Código de Comercio expresan los profesores Herrera Espinoza y Guzmán García, (2009) que las normas del Código Civil carecen de vigencia por las siguientes razones:

- Las disposiciones del Código de Comercio derogan tácitamente las del Código Civil, porque las primeras son posteriores en el tiempo, el Código de Comercio entró en vigencia el 30 de enero de 1917, mientras que el Civil es del año 1904, además que ambas normas son en buena medida coincidente.

- El art. 536 del Cc establece que "los contratos de seguros de cualquier especie, siempre que sean hechos por empresas serán mercantiles", disposición que se relaciona con lo establecido en la Reforma de la LGIS que únicamente pueden ejercer la actividad de asegurar y reasegurar las personas jurídicas constituidas y domiciliadas en el país como Sociedades Anónimas. 
En sentido contrario, el jurista Habed Blandón (2007), manifiesta que dada la importancia de la actividad aseguradora y considerando los vacíos que contienen las disposiciones del $\mathrm{Cc}$ en materia del Contrato de Seguro, se aplican también de manera supletoria las normas del C, relativas a este contrato (art. 2 del Cc.), y detalla que normas a su criterio si están derogadas por el Cc y la LGIS y cuales están vigentes, a saber:

Los arts. $3539 C$ derogado por el art. 534 Cc, 3541 derogado por el art. $537 \mathrm{Cc}, 3544 \mathrm{C}$ derogado por el art. 542, 580, 587Cc, $3546 \mathrm{C}$ derogado por los art. 538, 578, y $586 \mathrm{Cc}, 3547$ derogado por el art. $546 \mathrm{Cc}, 3548 \mathrm{C}$ derogado por art. $543 \mathrm{Cc}, 3549 \mathrm{C}$ derogado por los arts. 543 y $544 \mathrm{CC}$, los arts. 3551, 3552, 3553, 3557, 3558 derogados por el art. 2 LGIS, 3554 derogado por art. 545 y $547 \mathrm{Cc}, 3556 \mathrm{C}$ derogado por el art. $550 \mathrm{Cc}, 3556$ derogado por el art. $550 \mathrm{Cc}, 3559 \mathrm{C}$ derogado por el art. 552Cc, $3566 \mathrm{C}$ derogado por el art $548 \mathrm{Cc}, 3567 \mathrm{C}$ derogado por el art. 542 y $580 \mathrm{Cc}$, 3570 derogado por el art. $553 \mathrm{Cc}, 3574$ derogado por el art. $555 \mathrm{Cc}, 3577$ derogado por el art. 538 y $586 \mathrm{Cc}, 3578$ derogado por el art. 51 LGIS, 3584 derogado por el art. 27 LGIS [este artículo mantiene su vigencia, ya las disposiciones no son contradictorias, lo que hace es ordenar la clasificación de las operaciones de seguros, puesto que los numeral 2, 3 y 4 engloban en la categoría de daños del citado artículo y el 1 al seguro de personas], $3585 \mathrm{C}$ derogado por el art. $585 \mathrm{Cc}, 3586 \mathrm{C}$ derogado por el art. $587 \mathrm{Cc}, 3589 \mathrm{C}$ derogado por el art. $590 \mathrm{Cc} .3599$ derogado por el art. 583 Cc, y 3942 derogado tácitamente [la aplicación de este artículo no entra en contradicción con otro artículo, que prohíba expresamente la aplicación del mismo, lo que es evidente es el desuso de tal disposición].

En consecuencia de lo anterior, mantienen su vigencia los siguientes artículos del Código Civil, 3540, 3542, 3543, 3545, 3550, 3555, 3560 al 3565,3568 al 69, 3571, 3573, 3575, 3576, 3579, 3580 al 83, 3587, 3588, $3590 \mathrm{al} 3598,3600$ al 3606 y $3778 \mathrm{C}$.

Realizados los planteamientos anteriores, concordamos con el criterio de mantener la vigencia de las disposiciones del Código Civil, en tanto no contradigan las disposiciones del Cc y LGIS y su reforma, por ser normas posteriores en el tiempo y tomando en cuenta la aplicación del Título Preliminar del Código Civil XXXV referido a la derogación de las leyes "Es tácita, cuando la nueva ley contiene disposiciones que no pueden conciliarse con las de la ley anterior”. Para reforzar más este criterio hacemos propios el comentario de los profesores Herrera Espinoza \& 
Guzmán García, (2009) quienes sostienen que en su mayoría las normas del Código Civil son coincidentes con las del Código de Comercio.

El Título II de el Proyecto de Ley General de Instituciones de Seguros, Reaseguros y Fianzas (en adelante Proyecto de LGISR) regula lo relacionado con las Sociedades de Seguros y el Título V a los Contratos de Seguros (art. 73 al 83), pero no deroga expresamente las disposiciones contenidas en el Código de Civil y el Código de Comercio, únicamente señala que se derogan todas las disposiciones que se le opongan (art. 193 inciso d).

Es importante aprovechar la reforma, para armonizar e incluir en el proyecto las disposiciones del Código Civil y Mercantil que mantendrán en vigencia, esto facilitará el estudio de la materia a la par de evitar contradicciones y ambigüedades entre ambas cuerpos jurídicos. La propuesta es realizar un texto refundido que incluya tanto las normas del Código Civil y las del Código de Comercio, ese texto puede ser la LGISR.

Lo anterior, se relaciona con el contrato de seguro, lo que algunos juristas como Sánchez Calero (2002) y Herrera Espinoza \& Guzmán García (2009) denominan parte del Derecho privado del seguro (normas de carácter de derecho dispositivo), dentro de la rama jurídica denominada Derecho de Seguros, en contraposición el Derecho público de seguros (normas de carácter administrativo) dictadas para el control de la actividad aseguradora. El análisis de este estudio se centrará en las normas relacionadas a los seguros denominadas de Derecho público.

Sobre esta regulación en particular conviene precisar sus propios antecedentes, según Argüello Ramirez (2007).

Desde la Década de los 40 se comenzaron a dictar normas jurídicas que tendían a la regulación de la banca y de los seguros, sin organizar entonces un buen sistema de control, el cual comienza a desarrollarse con la creación del Banco Central de Nicaragua. Dentro de esta ley se le adscriben las funciones de supervisión de la banca central y de la banca privada a la Superintendencia de Bancos y de Otras Instituciones, funciones que luego se amplían, con la Ley General de Bancos y de Otras Instituciones del 16 de Abril de 1963, a la supervisión de "toda 
persona natural o jurídica de carácter privado que no fuere un banco o una institución de ahorro y préstamo para la vivienda que quisiere recibir o recibiere cuotas de dinero del público, ofreciendo en cambio devolver, entregar, vender o ceder en el futuro mercaderías, servicios, inclusive los fúnebres, terrenos o casas o sumas de dinero." (art. 242 LGB). Con la Ley 316 que regula la Superintendencia de Bancos y de Otras Instituciones Financieras se ha limitado el campo de supervisión de la misma a las siguientes entidades financieras (art. 2): bancos, sucursales y agencias bancarias estatales, privadas, nacionales y extranjeras, instituciones financieras no bancarias definidas en el art.126 LGB como las que prestan servicios de intermediación bursátil o servicios financieros con recursos del público (entre las cuales están las empresas de seguro), y, grupos financieros definidos en el art. $130 \mathrm{LGB}^{33}$ (p. 38).

En Nicaragua, las principales disposiciones jurídicas en materia de seguros son: El art. 99 Párrafo cuarto de la Constitución Política de Nicaragua (Cn), la Ley General de Instituciones de Seguro (en adelante LGIS), Decreto No. 1727 del 4 de agosto de $1970^{34}$, y su reforma por la Ley No. 227, del 26 de julio de $1996^{35}$, el Reglamento de Reforma de la LGIS Decreto No. 25-96 $6^{36}$ y las Normas Técnicas (en adelante NT) que dicte la SIBOIF en el ámbito de su competencia.

Actualmente se encuentra en la Comisión Económica de la Asamblea Nacional el Proyecto LGISR, que ya fue dictaminado por dicha Comisión. El proyecto contiene un total de 193 artículos, divido en IX Títulos, su art. 1 establece el objeto de la ley:

Objeto.- La presente Ley es de orden público e interés social y tiene por objeto regular la constitución y el funcionamiento de las sociedades o entidades de seguros, reaseguros, fianzas y sucursales de sociedades de seguros extranjeras; así como la participación de los intermediarios y auxiliares de seguros, a fin

33 Para referencia del lector, el Banco Central de Nicaragua (en adelante BCN) fue creado de conformidad con el Art. 148 inc. 19 de la Constitución Política de 1950. Mediante Decreto Legislativo No. 525 del 16 de Septiembre de 1960. Sus operaciones las inició el 1 de Enero de 1961, como una institución del Estado con autonomía funcional, duración indefinida, patrimonio propio y personalidad jurídica. 
de velar por los derechos del público y facilitar el desarrollo de la actividad aseguradora.

Es función especial del Estado, a través de la Superintendencia de Bancos y otras instituciones financieras, velar por los intereses de los asegurados que confían sus primas a las instituciones de seguros, reaseguros o fianzas y a sus intermediarios, que estén legalmente autorizadas y registradas para realizar tales operaciones. En la aplicación de la presente Ley, el Estado deberá reforzarla seguridad y la confianza del público en dichas instituciones, promoviendo una adecuada supervisión que procure la liquidez y solvencia de las instituciones regidas por esta Ley, procurando un desarrollo equilibrado del sistema asegurador que genere una sana competencia y cartera de productos diversificados y eficientes para los consumidores...

Como podemos notar, en el artículo antes transcrito, no se incluye como objeto del proyecto de LGIS, lo relacionado a la regulación del contrato de seguro, tema que queda pendiente de actualización jurídica. Lo más recomendable es aprovechar la reforma para incluir en un único cuerpo normativo la regulación pertinente a los seguros, al menos los temas que son fundamentales.

\section{Principios básicos de seguros (PBS)}

Para contribuir al crecimiento económico de un país, el sector asegurador debe operar sobre una base financiera sana, en este sentido un sistema de regulación y supervisión es necesaria para mantener mercados de seguros solventes y estables.

Dichos mercados protegen y benefician al asegurado, para el jurista Sánchez Calero "asegurado es la persona que es titular del interés asegurado y que por consiguiente, está expuesta al riesgo" (2010, p. 388). Para efectos de esta investigación también se le denominará consumidor, entendido éste último como el destinatario final de un bien o servicio (véase definición contenida en el art. 4 de la Ley de Defensa de los Consumidores publicada en La Gaceta, Diario Oficial No. 213 del 14 de noviembre de 1994 y el art. 4 inciso d) del Proyecto de Ley de Protección a los Derechos de los Consumidores y Usuarios). 
En la actualidad existe un conjunto de principios básicos de supervisión y recomendaciones internacionales establecidos por la IASIS [Asociación Internacional de Supervisores de Seguros, por sus siglas en inglés, ASSAL en español]. Este es un organismo internacional que agrupa a las máximas autoridades supervisoras de la actividad de seguros de Latinoamérica. En él participan 21 países, 19 países latinoamericanos como miembros de pleno derecho y 2 miembros adherentes, España y Portugal. Nicaragua forma parte de Assal.

En 1979 se aprobó el Estatuto para la creación de Assal, en la ciudad de Buenos Aires, Argentina; sin embargo esta iniciativa no se concretará hasta 1991, en la II Asamblea, en la que participaron 18 países de América Latina. (Assal, 2010).

Assal (2010) estableció estos principios para efectuar una adecuada supervisión coherente, transparente y confiable del mercado asegurador. Estos principios y recomendaciones muestran una clara tendencia hacia un sistema de supervisión centrado en el análisis de los riesgos y su gestión por parte del asegurador, al que se le denomina modelo de Supervisión Basado en Riesgos (SBR), modelo que seguirá Nicaragua, según en el art. 5 numeral 4 del proyecto de LGISR que más delante abordaremos.

Para Macías Muñoz \& Perez Jiménez, la Assal identifica los principales elementos deun régimen desupervisión, queconstatanto decomponentes cuantitativos (financieros) como cualitativos (gobernabilidad y comportamiento del mercado, en el que se incluyen la protección de los asegurados). Este modelo desarrolla un enfoque más preciso respecto de cómo operar un régimen de solvencia y las implicancias de éste en términos de cómo estructurarse. (Instituto de Ciencia del Seguro. Fundación MAPFRE, 2008).

En la siguiente figura se aprecia la estructura y normas comunes de solvencia y el rol de divulgación dentro del marco para la supervisión de seguros de la Assal: 


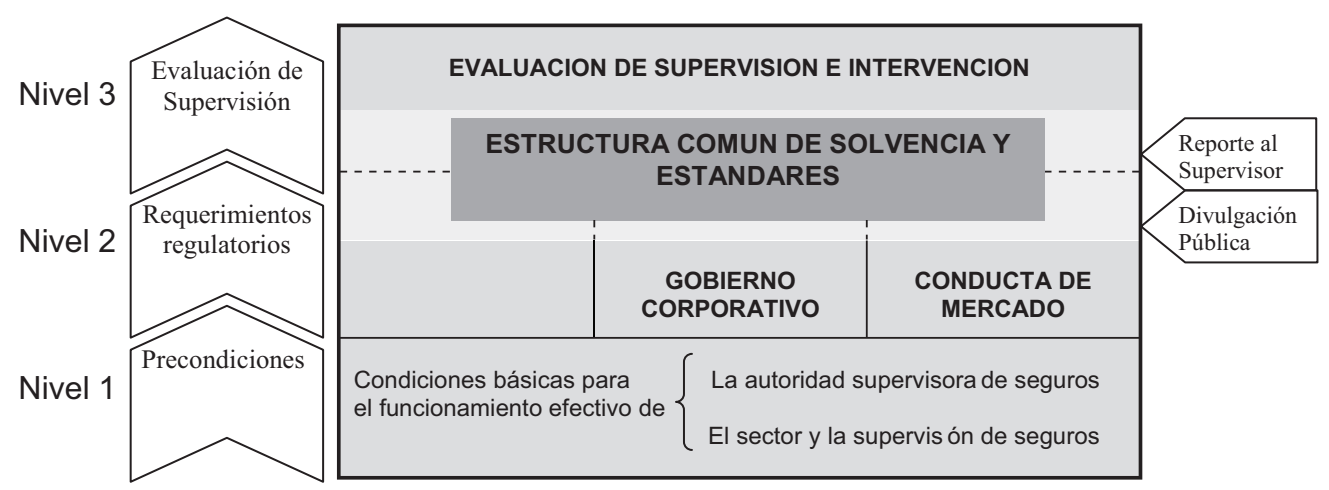

El enfoque presenta la existencia de tres niveles: un primer nivel de precondiciones para la evaluación de la solvencia; un segundo nivel de requisitos reglamentarios, el que incorpora requisitos financieros, de gobernabilidad y de comportamiento de mercado; y un tercer nivel de evaluación e intervención de supervisión; a estos tres niveles se agrega el rol de divulgación. En la divulgación pública se hace necesario contar con una divulgación pública e informes confidenciales adicionales para el supervisor, y para que el propio régimen de solvencia sea transparente.

La Assal ha sugerido que estos principios se constituyan en orientadores para los supervisores de seguros de todas las jurisdicciones y puedan ser utilizados para fortalecer el marco de supervisión de las jurisdicciones, evitar la sobre-regulación y promover la auto-regulación en esquemas competitivos. Así mismo, que estos principios son aplicables a la supervisión aseguradora y reaseguradora, ya sean privadas o controladas por el gobierno.

En total son 28 principios aprobados en la Asamblea General de la Assal en Octubre de 2003 en Singapur, que se resumen en seis grandes postulados que abarcan el contenido de los 28. A continuación se explican las definiciones de cada principio y las normas técnicas relacionadas, dictada por la SIBOIF:

\section{Condiciones para una supervisión efectiva}

Este principio engloba el PBS1 "Condiciones para una supervisión efectiva”, su enfoque es que se establezca un marco político, legal e institucional con: 
- Un sistema legal efectivo

- Estándares contables completos

- Experiencia en materia de auditoría contable y actuarial

- Efectiva infraestructura del mercado financiero

- Mercados financieros eficientes

La implementación del principio depende de la existencia de una política financiera y ambiente institucional sanos, así como de un sistema financiero e infraestructura legal que funcionen adecuadamente. El sistema legal debe proporcionar apoyo en honrar y hacer cumplir los contratos de seguros.

En el caso de Nicaragua, el cumplimiento de este principio se evidencia con las siguientes leyes y normativas:

- Políticas del Sector Financiero: Se cuenta con un marco legal e institucional- integrados por instituciones públicas, leyes y reglamentos- para el sector financiero, como: La Ley LGBIOF, Ley de la SIBOIF, LGIS y sus reformas, marco que está bien definido y es divulgado públicamente.

- En cuanto a la Infraestructura del sistema financiero, se han dictado NT sobre: Normas sobre Auditoría Externa, sobre Manual Único de Cuentas, entre otras.

\section{Sistemas de supervisión}

Aquí se engloban los PBS 2 Objetivos de la supervisión, PBS 3 Autoridad supervisora, PBS 4 Proceso de supervisión, y PBS 5 Cooperación e intercambio de información entre supervisores.

Los principales objetivos de la supervisión de seguros están claramente definidos. En este sentido, en la actual LGIS y su reforma no define con exactitud cuáles son los objetivos primordiales del supervisor, situación que cambia con el Proyecto de LGISR en cuyo art. 5 se establece expresamente el mandato y las responsabilidades de la autoridad supervisora.

Los principios giran alrededor de que la entidad supervisora cuenta con poderes adecuados, la protección legal y los recursos financieros para ejercer sus funciones y atribuciones en forma operativa independiente 
y rinde cuentas del ejercicio de sus funciones y atribuciones; contrata, entrena y mantiene suficiente personal con altos estándares profesionales trata la información confidencial en forma apropiada, y realiza sus funciones de una forma transparente.

\section{La entidad supervisada}

Aquí se refieren a los PBS 6, 7, 8, 9 y 10.

PBS 6 Aautorización de empresas de seguros

Los arts. 2, 3 y 4 de la Reforma a la LGIS establecen una definición de quienes pueden ejercer la actividad aseguradora, la nacionalidad de las mismas y lo relacionado a la actividad aseguradora, reaseguradora y de inversión. En el capítulo II de la misma reforma, nos encontramos el proceso de organización y autorización para funcionar. De los cuales destacamos:

- Se requiere la autorización de las aseguradoras, y prohíbe las actividades de seguros no autorizadas.

- Se define las figuras jurídicas permitidas de asegurar.

- Se asigna la responsabilidad para emitir autorizaciones.

- No se incluye una definición de aseguradoras, pero el proyecto de LGISR mejora este aspecto y define a las aseguradoras como: "Cada vez que esta Ley utilice el término de entidades de seguros, sociedades o sus similares, tanto en mayúsculas como en minúsculas, singular o plural, se entenderá que se trata de entidades que operan en seguros, reaseguros, fianzas y reafianzamiento, nacionales o extranjeras, de propiedad privada, estatal o mixta, salvo las excepciones expresamente contempladas en esta Ley”. (art. 1 último párrafo).

PBS 7 Idoneidad de las personas

Los accionistas mayoritarios, miembros del consejo de administración, altos directivos, auditores y actuarios de una institución de seguros son el personal idóneo y apropiado para llevar a cabo sus funciones. Esto requiere que tengan la integridad, capacidad, experiencia y calificación apropiada. 
En este sentido, ver las NT: Norma sobre Requisito para ser Director, Gerente General y/o Ejecutivo Principal y Auditor Interno de Instituciones Financieras (CD-SOBOIF-597-3-SEP9- 2009 del año 2009), Norma sobre Contenido mínimo del Código de Conducta para Directores, Gerentes Generales, Auditores Internos y Empleados (CDSIBOIF- 536-1-JUN4-2008 del año 2008), Proyecto de Norma sobre Conflicto de Intereses y Código de Conducta para el personal nombrados por el Superintendente (CD-SIBOIF-209-1-JUL4-2002 del año 2002), en este mismo sentido el capítulo III, art. 52 al 62 de la LGIS, véase el art. 52 de la Reforma LGIS.

\section{El PBS 8 Transferencia de cartera y fusión}

Se refiere a que la autoridad supervisora aprueba la transferencia de cartera o la fusión de las operaciones de seguros. En este sentido, ver NT sobre Norma para Reforma a la norma para el traspaso, transferencia o adquisiciones de instituciones financieras supervisadas (CD- SIBOIF-476- ABR25-2007) y su reforma mediante Resolución CDSIBOIF-530-2-ABR16-2008 del año 2008, esta normativa establece que las personas que quieran adquirir acciones en porcentajes mayores o iguales al $5 \%$ de la instituciones supervisadas deben obtener autorización de la SIBOIF. La autoridad supervisora establece requerimientos para evaluar las solicitudes de aseguradores para transferir todo o alguna parte de su operación de seguros.

\section{PBS 10 Control interno}

La autoridad supervisora requiere que los aseguradores tengan en funcionamiento controles internos, que sean adecuados para la naturaleza y escala de su operación. Los sistemas de vigilancia y reportes permiten al consejo de administración y a los directivos monitorear y controlar las operaciones.

\section{El Proceso de supervisión (supervisión continua)}

Para la correcta aplicación de este postulado se engloban los PBS 11 al 17.

PBS 11 Análisis de mercado

Utilizando todas las fuentes disponibles, la autoridad supervisora monitorea y analiza todos los factores que pudieran tener un impacto 
en las aseguradoras y en el mercado de seguros. El supervisor llega a conclusiones y toma las acciones en forma apropiada.

PBS 12 Reportes al supervisor y monitoreo de escritorio

La autoridad supervisora establece los requerimientos para la entrega periódica y sistemática de información financiera y estadística, informes actuariales y otra información de todos los aseguradores autorizados en la jurisdicción. En este sentido, véase el art. 29 de la LGIS que establece el cumplimiento fiel a este principio.

PBS 13 Inspecciones en sitio

Las inspecciones in situ constituyen una herramienta fundamental en la supervisión. La autoridad supervisora lleva a cabo visitas de inspección para revisar las operaciones de una aseguradora y su cumplimiento con la legislación y los requerimientos de supervisión.

Este principio se refiere a que por ley, la autoridad supervisora debe contar con amplios poderes para llevar a cabo visitas de inspección y para obtener información que estime necesaria para cumplir con sus deberes, esta facultad está establecida en el art. 64 de la LGIS y 3.8 de la Ley 316.

PBS 14 Medidas preventivas y correctivas

La autoridad supervisora toma medidas preventivas y correctivas que son oportunas, apropiadas y necesarias para lograr los objetivos de la supervisión de seguros.

PBS 15 Sanciones y medidas obligatorias

La autoridad supervisora hace cumplir acciones correctivas y, cuando es necesario, impone sanciones basadas en criterios claros y objetivos que son divulgados públicamente. La autoridad supervisora puede emitir instrucciones formales a las compañías para que tomen acciones específicas o para que se desistan de tomarlas. El no cumplir con una instrucción formal emitida por la autoridad supervisora tiene consecuencias serias para aquellos que realizan dicha acción (arto. 64 LGIS). 
PBS 16 Liquidaciones y salida del mercado

El marco legal y regulatorio define un rango de opciones para la salida ordenada de aseguradoras del mercado. Define insolvencia y establece los criterios y procedimientos para tratar con la misma. En el caso del procedimiento de liquidación, el marco legal da prioridad a la protección de los asegurados.

\section{PBS 17 Supervisión de grupos}

La autoridad supervisora supervisa a las aseguradoras sobre una base individual y de grupo.

\section{Requerimientos prudenciales}

Esta sección establece seis principios que abordan cuales son los requerimientos prudenciales. Su objetivo común es garantizar que las aseguradoras tengan la capacidad, bajo todas las circunstancias razonablemente predecibles, para cumplir con sus obligaciones conforme éstas se presenten.

PBS 18 Evaluación y administración de riesgos

La autoridad supervisora requiere que las aseguradoras reconozcan el rango de riesgos que enfrentan y los evalúen y administren con efectividad.

PBS 19 Actividad aseguradora

Dado que la actividad principal del seguro es la asunción o toma de riesgos, la autoridad supervisora requiere que los aseguradores evalúen y administren los riesgos que suscriben, especialmente a través de la constitución de reservas técnicas y matemáticas y el reaseguro, y que cuenten con las herramientas para establecer un nivel adecuado de primas.

\section{PBS 20 Pasivos}

La autoridad supervisora requiere que los aseguradores cumplan con estándares para establecer reservas técnicas suficientes y otros pasivos, y hacer posibles las recuperaciones de reaseguro. La autoridad 
supervisora tiene tanto la autoridad como la capacidad para valorar qué tan adecuadas son las reservas técnicas y para requerir que estas reservas se incrementen, en caso necesario.

\section{PBS 21 Inversiones}

La autoridad supervisora requiere que los aseguradores cumplan con estándares en sus actividades de inversión. Estos estándares incluyen requerimientos sobre la política de inversión, mezcla de activos, valuación, diversificación, ajuste de activos y pasivos, y administración de riesgos financieros.

PBS 22 Derivados y obligaciones similares

La autoridad supervisora requiere que los aseguradores cumplan con estándares para el uso de derivados ${ }^{37}$ y obligaciones similares. Dichos estándares abordan restricciones en su uso y requerimientos de divulgación, así como controles internos y monitoreo de las posiciones relacionadas.

PBS 23 Suficiencia de capital y solvencia

La autoridad supervisora requiere que los aseguradores cumplan con el régimen desolvencia establecido. Esterégimen incluyelos requerimientos de capital y requiere formas de capital adecuadas que permitan que la aseguradora absorba pérdidas significativas imprevistas.

\section{Mercados y consumidores}

Los siguientes principios se refieren a temas relacionados con la conducta de mercado que son un área esencial de la supervisión en el sector asegurador, y pudiera tener un riesgo de reputación o impacto prudencial en las aseguradoras.

\section{PBS 24 Intermediarios}

La autoridad supervisora establece requerimientos, directamente o a través de la supervisión de las aseguradoras, para la conducta de los intermediarios (en este sentido véase art. 82, 83 y 84 LGIS).

37 Derivados: es un activo o pasivo financiero cuyo valor depende de - o se deriva de - otro activo, pasivo o índice. Los derivados también son contratos financieros e incluyen un amplio rango de instrumentos, tales como futuros, opciones, swaps. 
PBS 25 Protección al consumidor

Los requerimientos para la conducta de la actividad aseguradora ayudan a fortalecer la confianza del consumidor en el mercado de seguros.

La autoridad supervisora requiere que los aseguradores y los intermediarios traten a sus clientes de una forma justa, prestando atención a sus necesidades de información. Respecto de los consumidores en su propia jurisdicción, la autoridad supervisora debe establecer requerimientos que los aseguradores e intermediarios deben cumplir. Requerimientos aplicables a las ventas transfronterizas también deben ser claros.

Un buen proceso de resolución de reclamaciones por siniestros es esencial para el trato justo a los clientes. Para este propósito, algunas jurisdicciones han establecido mecanismos de resolución de reclamaciones por siniestros extrajudiciales, tales como mediación o arbitrajes.

PBS 26 Información, divulgación y transparencia hacia el mercado

La autoridad supervisora requiere que las aseguradoras divulguen información relevante sobre una base oportuna a efecto de proporcionar a los interesados una visión clara de sus actividades del negocio y de su posición financiera y para facilitar el entendimiento de los riesgos a los que se encuentran expuestos.

\section{PBS 27 Fraude}

La autoridad supervisora requiere que las aseguradoras y los intermediarios tomen las medidas necesarias para prevenir, detectar y remediar los fraudes de seguros.

El fraude de seguros resulta en daños financieros y a la reputación, así como en costos sociales y económicos. Es por ello que la autoridad supervisora requiere que las aseguradoras y los intermediarios aborden estos asuntos de una manera efectiva. 
PBS 28 Combate al lavado de dinero y al financiamiento al terrorismo

La autoridad supervisora requiere que los aseguradores y los intermediarios, como mínimo aquellos aseguradores e intermediarios que ofrecen productos de seguros de vida u otras inversiones relacionadas con los seguros, tomen medidas efectivas para detener, detectar y reportar lavado de dinero y el financiamiento al terrorismo consistentes con las recomendaciones de la Fuerza de Trabajo de Acción Financiera sobre Lavado de Dinero (Véase la Texto completo y Refundido de la norma para la Gestión de PLD/ $\mathrm{FT}^{38}$ ).

\section{El control de las empresas de seguros}

Al hablar de control nos referimos a la fiscalización, supervisión, vigilancia y el control mismo de la actividad aseguradora.

Se define el control como el rol del Estado que se traduce en el examen administrativo de la actividad aseguradora llevada a cabo por las compañías de seguros y coincide con la doctrina que afirma que la gravitación que los seguros ejercen en los diversos órdenes de la actividad mercantil justifica, con carácter tuitivo, la intervención del Estado para que la actividad aseguradora respete no solo los intereses de los particulares de los asegurados y aseguradores, sino también los generales de la comunidad. (Leiva Fernández, 2009).

Stiglitz (2008) considera que:

el poder policía y control del Estado sobre la actividad aseguradora privada y se refiere a que la potestad reguladora implica una actividad delimitativa de los derechos de los particulares, de tal modo que, la policía se traduce en potestades jurídicas que ejerce el Estado a los fines de compatibilizar los derechos de los particulares con el bien común (p.45).

La regulación estatal hace un control permanente que se extiende desde la autorización para operar hasta la cancelación.

En este mismo orden de ideas, existen dos modelos recomendados internacionalmente para que los Estados a través de las entidades de supervisión realicen la misma. Uno es el propuesto por Assal, el modelo

38 Publicada en La Gaceta, Diario Oficial, No. 62 del 31 de marzo de 2009. 
de SBR, del cual se expuso su enfoque principal en el apartado 2 PBS y otro es el modelo normativo, que las grandes economías han abandonado para adoptar el sistema propuesto por Assal.

\section{De la finalidad del control y su normativa}

Para Argüello (2007) significa diseñar y poner en práctica modelos de supervisión que le permitan analizar con la anticipación suficiente la situación financiera de las empresas de seguro, con el objeto de tomar las medidas correctivas antes de que sucedan situaciones que pongan en peligro la sanidad financiera de ellas.

A esto le podemos agregar, que el Estado a través del órgano de control, realiza la vigilancia en consideración a la protección de la agrupación de asegurados que, de lo contrario, se hallaría desprotegida.

La finalidad del control en sí misma gira en torno a dos elementos, la sanidad financiera del país y la protección de los asegurados.

El art. 5 del proyecto de LGISR consagra expresamente cuales son los objetivos de la supervisión estatal, es decir, qué es lo que se controla, aquí se responde desde cuándo y hasta dónde el Estado vigilará,

"1. Regular la actividad de seguros, reaseguros y fianzas, su intermediación y comercialización, de tal manera que el mercado asegurador sea dinámico, transparente y organizado.

2. Fomentar la transparencia en perfiles de riesgos y calidad de las sociedades de seguro, tanto para otorgar incentivos correctos a sus usuarios, como para un eficiente manejo del mismo.

3. Contribuir al establecimiento de un sistema asegurador moderno y eficiente, atendiendo criterios técnicos de especialización en el campo de los seguros, reaseguros y fianzas según los ramos u operaciones que realicen.

4. Actualizar las modalidades o metodologías de supervisión adecuándolas a las mejores prácticas internacionales y enfocadas en una supervisión basada en riesgo.

5. Velar por la liquidez y solvencia de las sociedades de seguros, reforzando la seguridad y confianza del público en éstas; así como generar una sana competencia y cartera de productos diversificados y eficientes para los usuarios. 
6. Garantizar protección de los derechos de los usuarios o clientes quienes confían sus primas a las instituciones de seguros, reaseguros o fianzas y a sus intermediarios, como asimismo vigilar por el respeto de los mismos frente al desenvolvimiento del mercado de seguro.

De lo anterior, podemos destacar que se plasma en el proyecto LGISR las finalidades de la supervisión, se agrega la adopción de un modelo de SBR, numeral 4, que es el modelo de supervisión propuesto por Assal. Ahora bien, ¿Qué significa supervisión basada en riesgo?.

Que Nicaragua se inserte en las nuevas tendencias de supervisión que siguen los países modernos, dejando atrás los modelos de supervisión normativos. Basado en riesgo significa:

- Aplicar técnicas cuantitativas a la evaluación de los riesgos presentados por las instituciones de seguros, para informar respuestas de supervisión estratégica.

- Permitir un enfoque proactivo para adelantarse a los problemas.

- Apoyar una postura pública en el sentido que la acción supervisora no evitará la materialización de todos los riesgos.

Por supuesto, lo anterior lleva a implementar NT especializadas para cumplir con la elaboración de perfiles de riesgo con sus respectivos indicadores, diseñando sistemas de alerta temprana y llevando a cabo auditorías de gestión de esos riesgos.

Para vigilar la sanidad financiera es importante controlar los aspectos técnicos del negocio de seguros y lo relacionado a las inversiones que realizan las empresas de seguros con el fondo de seguros, que es la garantía principal que junto con el patrimonio de las aseguradoras tienen los asegurados. En consecuencia, deben establecerse criterios objetivos de alta seguridad, rentabilidad y liquidez, que permitan afrontar las situaciones de riesgo a que las empresas de seguro están sometidas.

De acuerdo con Argüello (2007) el control estatal busca que se cumplan los dos aspectos fundamentales del funcionamiento de la institución del seguro:

a) Su aspecto técnico, mediante la creación de un fondo de seguros que sea adecuado a las obligaciones de indemnización 
contraídas por la empresa. La técnica del seguro exige la formación de una masa homogénea de riesgos a los que están expuestas un conjunto de personas, quienes contribuyen con sus cuotas a la formación del fondo de seguros. Por ello es de suma importancia que la prima o precio del seguro sea suficiente para contar con los recursos necesarios cuando ocurran los siniestros. De allí la conveniencia de vigilar los costos operativos de la empresa y el de los riesgos asumidos. De lo dicho surge la importancia de la intervención actuarial en el cálculo correcto de la prima o precio comercial del seguro;

b) Su función social, de amparo a los asegurados que sufran los siniestros mediante el pago de la indemnización por la pérdida sufrida a consecuencia del riesgo asegurado. Esta función que se basa en el principio de solidaridad distribuye las pérdidas causadas por un siniestro entre la masa de asegurados que contribuye con el pago de sus primas a la formación el fondo de seguros (p. 40).

Según funcionarios de la SIBOIF, las inspecciones in situ que realizan son de dos tipos, una de carácter técnico y otro administrativo. Por la importancia para la sanidad financiera nacional, el $90 \%$ de las inspecciones se enfocan en aspectos de tipo técnico y un 10\% en lo administrativo. Centrando su interés en aspecto técnico dejando a un lado la función social que es parte primordial de la misma.

Contar con un sistema adecuado de supervisión otorga beneficios a los asegurados, compañías de seguros y a toda la población en general y debe enfocarse en cumplir con ambas funciones.

La normativa que regula el control y supervisión, a la fecha podemos contabilizar alrededor de 90 disposiciones, entre leyes y sus reformas, NT y sus reformas, Interpretaciones de artículos, circulares e instrucciones, que regulas temas tales como: Actualización de Capital Mínimos de las Instituciones de Seguros, Normas de Conductas, Auditoría Interna y Externa, PLD/FT, Imposición de Multas, Procedimiento Administrativo, entre otros.

El modelo de supervisión adoptado por la SIBOIF, según los entrevistados están acorde con los estándares internacionales como las NIIF (Normas Internaciones de Información Financiera) adoptados en materias 
contables, Solvencias II (basado en tres pilares, el primero exigencias de recursos propios, el segundo proceso de supervisión y el tercero disciplina de mercado) y en cuando a la PLD/FT siguen las propuestas de GAFIC (Grupo de Acción Financiera del Caribe), GAFI (Grupo de Acción Financiera Internacional), por tal razón la normativa es abundante en el tema, además del dinamismo propio de la actividad financiera.

2. Tipos de controles que ejerce el Estado en la actividad aseguradora

La protección del interés público que representa la masa de asegurados se realiza a través de los diversos tipos de controles, a continuación se presentan.

\subsection{Del control económico y financiero}

El objetivo de este control se centra en el plano financiero y su finalidad principal es preservar la solvencia de las empresas aseguradoras, mediante la comprobación de que se realiza una gestión eficaz de las primas entregadas, que les permita estar siempre en la condición de asumir y cumplir sus obligaciones de pago de los siniestros. Este control se realiza a través de herramientas económico financieras.

El Estado pone relevancia al tema, porque esa acumulación de capitales de las empresas aseguradoras es parte del ahorro público y por ende debe vigilarse su administración y destino de la inversión.

El órgano de control deberá exigir que se cumplan con determinados parámetros económicos-financieros y con las calidades técnicas de la institución del seguro.

Son de carácter económico-financieros

a. La fijación de capitales mínimos y normas de preservación. Se establecen criterios normativos de gestión de las empresas aseguradoras, por su importancia destacamos:

a.1. Con ellos se pretende afrontar los gastos de establecimiento o de organización, los gastos de administración y de mercadeo, conocidos como "gastos de adquisición".

a.2. Se establece con carácter uniforme, el monto del capital mínimo y normas que preserven su integridad, ya que éste representa una garantía para los asegurados. La LGIS en su art. 8, parte 
final, establece el parámetro para la determinación del capital mínimo, que en la solicitud de autorización de una empresa de seguros, como parte del estudio económico financiero presentado, se indicará cual es "la proyección relativa a la determinación del capital.” Este es revisado por la SIBOIF y tomando como referencia a los siniestro.

El art. 30 de la LGIS establece que las cifras de capital mínimo necesario para que las aseguradoras puedan operar en determinadas modalidades o ramos de seguros, artículo es actualizado por El Consejo, la última actualización fue mediante la Resolución $\mathrm{N}^{\circ}$ CD-SIBOIF-6113-ENE22-2010 del 22 de enero de 2010 "Norma de actualización del Capital Social de las Compañías de Seguros", que establece como capital mínimo el siguiente:

Se actualiza el capital social mínimo requerido para las Compañías de Seguros, cuando operen de manera individual en el ramo de seguros de daños, veinte millones de córdobas $(C \$ 20,000,000.00)$; cuando operen de manera individual en el ramo de seguros de personas, veinte millones de córdobas (C\$20, 000,000.00); y cuando operen en ambos ramos, cuarenta millones de córdobas $(C \$ 40,000,000.00)$.

a.3. Preservación de la integridad del capital mínimo: Mantener el capital mínimo es necesario para afrontar sus obligaciones, en consecuencia debe la empresa incrementar su capital, en la medida en que aumenten sus operaciones.

Actualmente se habla del margen de solvencia, entendido como "la cantidad necesaria de recursos, determinados según la metodología de cálculo" definida por la SIBOIF, que mediante la Resolución No. CD-SUPERINTENDENCIA-XLIX-1-97 Norma relativa al Margen de Solvencia de las Instituciones de Seguros del 8 de enero de 1997, establece las cuantías mínimas del Margen de Solvencia para los ramos de seguros de: Vida y Daños, y la forma de cómo determinar el dicho margen.

También se controla la disminución del capital mínimo, el Plan de Normalización cuando la aseguradora presente problemas financieros (art. 89 LGBIOF).

b. Reservas de seguros ofondos de seguros. Estas son reservas técnicas y matemáticas. Estas reservas se constituyen o representan los beneficios no distribuidos o los excedentes no distribuibles que se 
hallan exentos de toda deuda del balance delas empresas aseguradora. Las reservas son de dos tipos, las legales y las técnicas.

En esta misma categoría encontramos las previsiones técnicas que se constituyen con el propósito de atender las obligaciones para con los asegurados, acreedores (pueden ser empresas reaseguradoras) y beneficiarios de contratos de seguros. Estas constituyen deudas del asegurador, características que le permite al asegurador reservar las sumas debidas bajo colocaciones reglamentadas por la SIBOIF.

La LGIS en su art. 33 y la NT sobre Constitución y Cálculo de Reservas, Resolución CD-SUPERINTENDENCIA-XLIX-I-97 del 8 de enero de 1997 y su modificación en noviembre de 2001 definen los tipos de reservas que debe constituir una aseguradora:

1. Las reservas Legales son: Las del capital, de su incremento y disminución

2. Las reservas técnicas son:

a. Reservas de Riesgo en curso para póliza vigente. Para cubrir los riesgos en curso totales por contratos de seguros.

b. Reservas para obligaciones pendientes de pago por beneficios exigibles de acuerdo con las pólizas.

c. Reservas de previsión para desviaciones estadísticas, y

d. Reservas para fluctuaciones de valores.

e. Otras Reservas, la SIBOIF podrá determinar con carácter general $\mathrm{y}$ uniforme las reservas de saneamiento de cartera y reservas adicionales de capitalización cuando las considere convenientes, dentro de los límites establecidos en el párrafo tercero del art. 32 de la LGIS.

Las instituciones aseguradoras deberán enviar a la SIBOIF, un informe detallado de valuación de todas las reservas técnicas y matemáticas, de las reservas de previsión y de riesgos catastróficos, detallando las sumas usadas y los cálculos efectuados para establecer los incrementos $\mathrm{y}$ decrementos de dichas reservas (art. 10 LGIS).

1. Inversiones. Están formadas por el capital, reserva de capital, las reservas técnicas y matemáticas, así como otras partidas de los activos y utilidades acumuladas, que representan las provisiones que permiten mantener la solvencia financiera de las instituciones 
de seguros. Los ingresos de las inversiones, denominados Ingresos Financieros, se ocupan para cubrir los costos de la operación de la aseguradora y aportar a la utilidad de la misma.

Estas provisiones constituyen un respaldo para los asegurados y los accionista, por ello debe el Estado garantizar y vigilar que se inviertan de la mejor forma satisfaciendo las exigencias de liquidez, diversificación y rentabilidad. Para garantizar los principios de seguridad, los artos. 35 a 39 de la LGIS y la Resolución No. CD-SIBOIF-428-1-JUN27-2006 "Norma sobre el Límite de Inversión de Instituciones de Seguros y Reaseguro", ambas normativas regulan las diferentes inversiones que pueden realizar en el país y en el extranjero las instituciones de seguros y reaseguros.

Los criterios a tomar en cuenta en materia de inversiones, activos elegibles y proporcionalidad de los máximos de inversión. A fin de preservar el destino de las reservas, la SIBOIF ha establecido los criterios a tomar en cuenta por las entidades, tales como:

- Monto máximo de inversión en el país y en el exterior. Las Instituciones de Seguros y Reaseguros podrán invertir el cien por ciento (100\%) de su Base de Cálculo de Suficiencia de Inversiones en el país y hasta un máximo del 20\% de la misma en el extranjero (art. 4 NT)

- Límites por tipo de inversión en el país y en el exterior (art. 7 y 8 de la NT y 35 LGIS), el listado de tipos de inversiones se anexa, para consulta del lector.

- Prohibición a las instituciones aseguradoras y reaseguradoras constituir cualquier tipo de gravamen sobrelos depósitos mantenidos en, o las inversiones en títulos emitidos por, otras entidades (art. 12 de la NT).

Son de carácter técnico los relacionados con las bases actuariales

Las bases actuariales se exigen para calcular el costo de los riesgos a cubrir con los diversos tipos de seguros, para lo cual deben elaborarse los respectivos planes técnicos y los textos de los contratos de seguros, los que se identifican con el nombre de pólizas de seguros.

El examen de los planes técnicos por la autoridad de control estatal permite establecer la solidez de los presupuestos técnicos económicos sobre los cuales se intenta poner la empresa en marcha. 
Estos planes deben contener: 1) las tarifas de primas a aplicar y sus fundamentos técnicos; 2) las bases para el cálculo de las reservas técnicas; 3) el texto de las pólizas que se propone emitir. (art. 15 de la LGIS).

Para solicitar la autorización para operar, las aseguradoras deberán presentar los modelos de pólizas y demás documentación señalada en el art. 15, así como las tarifas de primas y extraprimas, incluso las desviaciones del riesgo estándar, de los diversos planes de seguros, siendo obligatorio para el caso de seguros de vida remitir las bases de cálculos y las tablas de mortalidad usadas para el cálculo, los valores garantizados (de rescate, seguro saldado y seguro prorrogado) correspondientes a los diversos planes de seguros de vida; y por último la participación que de las utilidades de cada uno de los planes o del negocio repartirá entre sus asegurados, si está en su planificación o diseño del plan del seguro específico.

El régimen de control, está constituido por una serie de medidas preventivas complementadas con un sistema de sanciones por infracciones debidamente tipificadas, siempre respetando el derecho de defensa de la aseguradora.

Así mismo, está relacionada con el régimen de control, las normas relacionadas a la PLD/FT y es aplicable a las instituciones de seguros la NT sobre PLD/FT y sus reformas.

Encontramos que son instrumentos de control de las operaciones de las aseguradoras que se usan en el desarrollo normal de sus actividades por parte de las SIBOIF. Entre ellos podemos mencionar:

a. El Catálogo de cuentas. Mediante la Resolución No. CD-SIBOIF-4653-FEB7-2007, la SIBOIF estableció el Manual Único de Cuentas para el registro contable de las operaciones de las empresas de seguros, cuyo objetivo es establecer las pautas que deberán establecer las instituciones de seguros para implementar un sistema de registro contable uniforme, de tal manera que los estados financieros que se presenten a las instituciones financieras sean uniformes y presenten la verdadera situación financiera, patrimonial y de la gestión de las instituciones. 
En Nicaragua como en el resto de Centroamérica se aplican en materia contable las llamadas NICS, sigla que significa Normas Internacionales de Contabilidad. En Estados Unidos de América el sistema de contabilidad usado se denomina GAAP, sigla en inglés que significa Principios de Contabilidad Generalmente Aceptados (Generally Accepted Accounting Principles).

b. El Control de los balances. Las aseguradoras deben enviar mensualmente a la Superintendencia sus Estados Financieros: Balance General y Estado de Ganancias y Pérdidas, dentro de los primeros 12 días de cada mes.

c. El Estado actuarial de pérdidas y ganancias. Este es un documento que elabora el Actuario de la empresa de seguros para poder analizar los verdaderos costos de operación de la misma. Recordemos que las primas de los seguros se calcularon con determinadas hipótesis, de tal manera que el estado actuarial es la comprobación de si tales hipótesis se adecúan a la realidad. Por ello dichos estados se hacen por cada tipo de seguros, para conocer si está llenándose el requisito de cumplir con los principios técnicos de suficiencia de primas de riesgo. De acuerdo con el art. 29 de la LGIS, dicho estado debe ser presentado anualmente a la Superintendencia, una vez que se ha cerrado el respectivo ejercicio social.

d. El control de las tarifas de las primas de seguros. El mayor peligro que corren las empresas de seguro es no tener las primas adecuadas para formar un Fondo de Seguros solvente, Por ello la supervisión estatal vigila que las tarifas de primas sean suficientes para enfrentar los siniestros. Requiere pues no sólo el cálculo actuarial del que hemos hablado y el conocimiento del profesional o profesionales que prestarán el servicio de actuaría a la aseguradora, sino también si ésta cumple con los principios en que se basa dicho cálculo. En el art. 46 de la LGIS se indican como requisitos para que la SIBOIF pueda aceptar las tarifas de las aseguradoras, que ellas observen "los principios técnicos de suficiencia y equidad” y que sean el "resultado de información estadística que cumpla exigencias de homogeneidad y representatividad." Si no se cumplieran con dichos requisitos, de conformidad con el art. 47 de la misma Ley, la Superintendencia "deberá prohibir la utilización....de la Tarifa correspondiente hasta que no se compruebe el cumplimiento del requisito respectivo.” 
e. El reaseguro de los contratos de seguro. Este es uno de los medios más eficaces de control estatal. Con el reaseguro se dispersa el riesgo y se incorpora en la responsabilidad de dichos contratos la figura del reasegurador, que se considera una empresa internacional financieramente más fuerte que el asegurador. Por ello la LGIS establece que ninguna aseguradora podrá asumir sin reasegurar los riesgos que excedan de la capacidad de retención de la misma (art. 40).

Los reaseguradores deberán ser de reconocida solvencia técnica y financiera. En las NT de Control de la SIBOIF se exige a las aseguradoras que presenten anualmente los estados financieros de sus reaseguradores con su debida calificación emitida por una calificadora de riesgos financieros reconocida internacionalmente, con lo cual se puede ejercer un control indirecto sobre la calidad del reaseguro con el que están protegidas las empresas de seguro, según la Norma Regulatoria de Reaseguros, Resolución No. CD-SUPERINTENDENCIA-XLIX-1-97 de fecha 8 de enero de 1997, modificada por Resolución No. CD-SIB-144-2ENE26-2001 de fecha 26 de enero de 2001.

\subsection{Del control interno (Organizacional)}

a. Autorización para operar

El control del Estado sobre este tema inicia con la autorización para operar, en la cual se regulan las condiciones mínimas para otorgar la autorización, regulado en los arts. 8 al 19 de la LGIS, por su transcendencia destacamos:

1. Deben tener como objetivo exclusivo efectuar operaciones de seguros (art. 8 LGIS) y una exposición explicativa de las razones de índole económica que justifiquen el establecimiento de la institución que se propone y la proyección relativa a la determinación del capital mínimo.

2. Son sociedades anónimas

3. Someterse al control de la SIBOIF.

4. Determinación de las ramas especificas para operar.

5. Aprobación de los planes de seguros, así como sus elementos técnicos y contractuales. Los planes deben contener la propuesta de pólizas, las primas y sus fundamentos técnicos. 
Esta solicitud es dictaminada por el Superintendente, el BCN y el Ministerio de Industria, Fomento y Comercio (MIFIC), solo podrán operar quienes hayan pasado por proceso de autorización y estén autorizadas por la SIBOIF. Las pólizas no requieren de aprobación de la SIBOIF, pero deben ser remidas a esta institución para verificar que no contengan cláusulas abusivas.

\section{b. Requisitos para ser funcionarios de empresas aseguradoras}

En cuanto a la organización, la LGIS y la Resolución No. CD-SIBOIF597-3-SEP23-2009 establece los requisitos para ser Directores, Gerente General y/o Principal Ejecutivo y Auditor Interno de las Instituciones de Seguros, y se incluye los criterios de calificación (art. 4 de la NT) y los requisitos a ser presentados (art. 6 de la norma técnica).

El objetivo de estas disposiciones es el fortalecimiento del gobierno corporativo, es decir el conjunto de directrices que regulan las relaciones internas entre la Junta General de Accionistas, la Gerencia, Funcionarios y Empleados; así como entre la institución, el ente supervisión y el público (art. 39 LGBOIF), para garantizar la honorabilidad, honradez y competencia que deben poseer las personas que ostentan estos cargos de los principales ejecutivos de estas instituciones.

Relacionado a lo anterior, está la Resolución No. CD-SIBOIF-536-1JUN4-2008 "Norma sobre el contenido mínimo del Código de Conducta para Directores, Gerentes y Auditores Internos y Empleados", que tiene como objetivo establecer la guía mínima del contenido de los Códigos de Conductas que deben tener las instituciones financieras, el cual es aplicable a los instituciones de seguros, con el fin de promover prácticas financieras sanas y la conducción de los negocios con rectitud y los más altos niveles de profesionalismo (art. 1).

Todo lo anterior guarda relación con el PBS número 7 y 9 relacionados en el punto 2 de este documento.

\section{c. Constitución de sociedades de seguros}

Únicamente pueden ejercer la actividad de asegurar las Sociedades Anónimas constituidas y domiciliadas en el País, éstas se constituyen al amparo de la regulación del Código de Comercio. 
El proyecto LGISR regula de forma más ordenada en los arts. 9 al 31 lo relacionado a las sociedades de seguros. Entre los aspectos más significativos de la reforma se encuentra el establecimiento de sucursales de sociedades de seguros extranjeras, la que podrán operar en el país, algo que actualmente no está permitido. El objetivo de esta norma es potenciar los Acuerdos de Libre Comercio que están en vigencia en el país, como el CAFTA-DR, para atraer la inversión extranjera.

\section{d. Suspensión o revocación de la autorización}

En este apartado el control abarca la suspensión o revocación de la autorización y el proceso de liquidación e intervención de las empresas aseguradoras. El art. 68 LGIS establece las causas expresas de revocación de la autorización para operar, tales como:

1. No iniciar operaciones con el público dentro de los 60 días hábiles siguientes a la fecha en que se comunique la respectiva autorización.

2. Las modificaciones que una institución extranjera introduzca a su constitución o a su funcionamiento, que afecten a la organización u operación de sus oficinas establecidas en Nicaragua, siempre que el Superintendente juzgue inconveniente que tales oficinas continúen operando dentro del nuevo régimen.

3. Que estando en suspenso su autorización para operar, dejare transcurrir el término que le hubiere fijado el Superintendente sin corregir o subsanar las causas que dieron origen a la suspensión.

4. Que la institución esté en insolvencia o en peligro inminente de caer en ella, que se disuelva o entre en estado de liquidación.

5. El hecho de que el capital de cualquier institución pasare en más del 50\% a poder de cualquier Gobierno extranjero o a nacionales de países con los que Nicaragua no tenga relaciones diplomáticas.

6. Esta disposición no sería aplicable a una Compañía constituida en Nicaragua que fuera subsidiaria de una compañía extranjera, ya que se trata de una persona jurídica independiente.

7. Cuando una empresa aseguradora se negase a pagar las indemnizaciones a que resulte condenada, por sentencia firme de los Tribunales nicaragüenses, o que siendo extranjera recurriere a la vía diplomática.

8. Cuando extendiese seguros no teniendo autorización para operar o estando esta suspensa, y

9. Cualquier otra causa establecida por la Ley. 
Es importante destacar que el proceso de revocación de la autorización, se sigue con las garantías del Debido Proceso (véase art. 60-70 LGIS), de lo contrario se violarían disposiciones jurídicas de orden constitucional.

El proceso de Intervención, liquidación y traspaso de cartera también está regulado en los arts. 72 a 77, donde el papel de la SIBOIF se vuelve determinante para garantizar el respaldo económico para el cumplimiento de las obligaciones adquiridas con los asegurados, y evitar un efecto negativo en la economía nacional. En concordia con lo anterior se encuentra la regulación del proyecto de LGISR art. 127 a 137.

Para evitar llegar a la intervención, la SIBOIF mantiene una vigilancia constante y en caso detectare problemas financieros puede intervenir, aprobando y estableciendo planes de normalización, si bien es cierto es parte del control de la solvencia sobre las empresas, también se asocia con el control organizacional, por estar relacionado con la revocación de la autorización.

El plan de normalización está destinado a que la empresa trate de solventar su situación financiera, éste deberá ser aprobado o rechazado por la SIBOIF en la medida que cumpla su objetivo, en el proyecto LGISR se establece de forma detallada en qué casos la SIBOIF podrá mandar a realizar un plan de regularización (véase art. 133 a 137).

En la actualidad no existe ningún caso registrado en la SIBOIF que haya llegado hasta la disolución, esto obedece a que ejercen un monitoreo constante sobre los aspectos del numeral 1 de este apartado.

\subsection{Del control de protección al consumidor}

Según Sánchez Calero (2002), la finalidad de este control es evitar la utilización de las condiciones generales por los aseguradores de aquellas consideradas como abusivas o ilícitas, la preocupación del Estado en este particular, es la protección a los asegurados, quienes se consideran el contratante más débil, no solo en el sentido económico, sino también a los efectos de conocer el alcance de la protección ofrecida por el asegurador.

En cuanto a los sistemas de protección del consumidor, la doctrina no se ha puesto de acuerdo respecto de su procedencia ni tampoco de las regulaciones sobre la defensa del consumidor. En cambio en otras 
legislaciones como la Argentina ha sido objeto de debate la figura del Defensor del Asegurado en apoyo del tomador individual del seguro brindándole protección, en la etapa previa de la celebración del contrato (precontractual), en su celebración y respecto de los efectos que se produzcan durante la vida del contrato. (Leiva Fernández, L. p. 42)

El marco normativo de protección de los derechos de los asegurados (consumidores), no está sistematizada en un solo cuerpo normativo y es importante aclarar, que por el tipo de relación que surge es aplicable a estas relaciones la Ley de Defensa de los Consumidores (LDC), en este sentido encontramos las siguientes:

a. El Control estatal sobre cláusulas contractuales. Retomamos los comentarios realizados en los antecedentes, las encontramos en el Código Civil y el Código de Comercio, lo que hace que existan controversias innecesarias ante los eventuales incumplimiento de las partes.

Se manifiestan en condiciones equitativas en las pólizas y precios adecuados a los riesgos asumidos, los art. 44 al 49 de la LGIS, establecen la revisión de los textos de las pólizas y de las tarifas por parte de la SIBOIF buscando la suficiencia y equidad, además de que dicha revisión exigirá a las aseguradoras que las pólizas cumplan con los requisitos de legalidad, claridad y detalle necesarios para expresar los derechos y obligaciones de los contratantes.

Así mismo, el art. 45 LGIS establece que la interpretación favorable al asegurado en caso de oscuridad en los términos o condiciones contractuales de las pólizas. Es la consagración del principio "In dubio pro consumatore" que también lo encontramos en la LDC art. 23.

b. La revocación de la autorización para operar cuandola aseguradora se negare a pagar su prestación en el contrato de seguro cuando hubiere sentencia firme de los tribunales de justicia nicaragüenses, art. 68 LGIS.

c. La prohibición de aplicar tarifas arbitrariamente discriminatorias o abusivas. El control se ejerce por la SIBOIF al iniciar operaciones y al controlar éstas durante la vida de la empresa arts. 15, inc. 2) y 46, inc. a) de la LGIS, relacionado a este tema está la protección contractual y del contrato de adhesión que otorga la LDC, arts. 21-24. 
d. El mercado de libre competencia. Hasta 1996 existió en Nicaragua el monopolio estatal, aunque es importante destacar que la empresa aseguradora estatal tiene ventajas frente a las empresas aseguradoras privadas y una que toma vital importancia es que se le permite usar los modelos de pólizas y las tarifas que el ex monopolio desee sin necesidad de previa autorización de la SIBOIF, esto afecta directamente a los aseguradoras pues quedan en clara desventaja con esta institución.

2.4. Normas que regulen el acceso a realizar reclamos por vías eficientes y eficaces y resolución de controversias

Algunos conflictos que pueden surgir entre asegurado y asegurador son: La reticencia y falsa declaración del riesgo, la propuesta del seguro y la póliza, la agravación del riesgo, entre otros. Por tal razón, es muy importante contar con los mecanismos idóneos para atender los reclamos y la resolución de controversias.

En este sentido, la regulación de la protección de los asegurados (art. 107 a 110 LGIS), únicamente se limita a establecer las condiciones de la póliza y tarifas y la protección que brindará la SIBOIF a los asegurados.

Es cierto se establecen sanciones, pero no existe un proceso claramente definido, que garantice los mínimos procesales para obtener una respuesta. Por otro lado nos encontramos con la LDC que establece el agotamiento de la vía administrativa ante el MIFIC- Dirección de Defensa del Consumidor, a través de un proceso que al final si el asegurado tiene una resolución a su favor y no es cumplida voluntariamente, tendrá que acudir a la vía judicial para tal efecto. Lo que genera costos y desgaste en el asegurado.

También encontramos NT que se pueden aplicar a la materia, un ejemplo es la Resolución No. CD-SIBOIF-454-1-NOV28-2006 de fecha 28 de noviembre del 2006 establece la "Norma para la tramitación de Recursos Administrativos", el art. 2 de la norma establece que los procedimientos para la tramitación de los recursos de revisión y de apelación en contra de las resoluciones dictadas por el Superintendente, el cual será de aplicación obligatoria tanto para el Superintendente, como para los recurrentes. 
Sobre este tema, expresaron funcionarios de la SIBOIF, que únicamente han llegado a la fecha dos casos utilizando la norma antes dicha, primero porque el Superintendente en caso de reclamo carece de facultades y en segundo lugar porque en estos temas no se emite una resolución como tal. Aunque expresaron que el número de reclamos de los asegurados ha aumentado considerablemente, del 2007 a la fecha.

Actualmente existen dos proyectos de leyes que regularán la protección del asegurado. El primero, el primero es el Proyecto de "Ley de Protección a los Derechos de los Consumidores y Usuarios" que en los arts. 83 a 93 establece la protección de los derechos de los usuarios financieros y bancarios, dentro de los cuales se incluye seguros. Estas disposiciones establecen las garantías mínimas de protección de los consumidores, pero el art. 93 establece:

Los usuarios tienen derecho a reclamar a las entidades financieras por el incumplimiento de las condiciones particulares, las condiciones generales establecidas por las entidades y las previsiones determinadas por la Ley en las operaciones relativas a los productos o servicios financieros prestados. Si la entidad bancaria o financiera no satisface el reclamo al usuario del servicio, éste lo interpondrá ante la Dirección de Protección al Consumidor, todo de acuerdo al procedimiento administrativo establecido en el Capítulo XXII de la presente Ley y su Reglamento.

Establece un proceso de reclamación ante las entidades financieras previo a utilizar la vía que establece la Ley de protección al Consumidor. La duda que se plantea es ¿QQuién vigilará porque existan estos procesos? La lógica apunta a que también será la SIBOIF. Actualmente todas las instituciones de seguros cuentan con manuales de reclamos, que no son aprobados por la SIBOIF, manuales que no son públicos ni facilitados a los consumidores, porque son políticas de gestión interna, lo que no ayuda a solucionar el problema.

El segundo es el proyecto de LGISR que en los arts. 84-92 regula el régimen de publicidad y protección al consumidor, que destaca los principios de: Libre competencia, Principios de transparencia y solidez de los productos, Publicidad y publicidad veraz, en este caso la SIBOIF podrá dictar normas de carácter general que regulen este tema. 
Los principales derechos que se reconocen son: Información alos usuarios de la industria del seguro, Libertad de contratación del consumidor del seguro, Autorización para cerrar al público, Confidencialidad de las operaciones, Derecho de comparecer ante la Superintendencia, en el último caso el proyecto LGSR, art. 92, establece:

Los usuarios de los servicios referidos en la presente Ley podrán comparecer ante el Superintendente o ante la instancia administrativa correspondiente para interponer quejas en contra de las entidades prestadoras de los servicios regulados por la presente Ley. El Superintendente dará audiencia a la respectiva entidad contra la cual se interpuso la queja para que dentro del plazo señalado por dicho funcionario, responda lo que tenga a bien. El Superintendente, sin perjuicio de las sanciones administrativas que amerite, dictará la respectiva resolución, pudiendo instruir la corrección respectiva en aras de restituir en sus derechos al usuario, en su caso.

En caso de incumplimiento de las resoluciones dictadas por el Superintendente o el Consejo Directivo por parte de las entidades prestadoras de servicios de seguros, se les aplicará una multa equivalente, conforme al artículo 170 de la presente ley.

Según lo anterior, le tocará a la SIBOIF crear un proceso administrativo que cumpla con las garantías antes mencionadas para atender los reclamos. En consecuencia, se estará hasta que se apruebe el proyecto y entre en vigencia que sabremos con exactitud qué posición adoptará el ente regulador sobre el tema, mientras tanto continuaremos con la carencia de dicha regulación.

No podemos dejar de mencionar que ciertamente carecemos de un proceso administrativo claro para interponer los reclamos, pero se desconocen y poco se utilizan los Métodos Alternos de Resolución de Controversias, regulados en la Ley No. 540, Ley de Mediación y Arbitraje, ${ }^{39}$ como la Mediación y Arbitrajes, mecanismos expeditos y más económicos para la resolución de controversias.

39 Publicada en La Gaceta, Diario Oficial, No. 122 del 24 de junio de 2005. 


\subsection{Del control reglamentario de los contratos de seguros}

Este control está referido a la regulación de los elementos técnicos y contractuales del contrato de seguro, normas de orden público e inderogable por voluntad de las partes.

En este sentido, la SIBOIF ejerce el control de legitimidad, equidad y claridad del contrato y de los textos que lo instrumentan. El contrato de seguro es un contrato de adhesión, ya que su contenido está predispuesto por la empresa aseguradora, lo que presupone un desequilibrio en la relación, solo factible de ser bloqueado por el ejercicio del control efectivo y debe realizarse el control sobre las cláusulas abusivas.

Este control administrativo debe ser efectivo, siendo inadmisible que la SIBOIF apruebe pólizas que contengan cláusulas abusivas.

Es así que las condiciones generales y los modelos utilizados por los aseguradores están sometidos a la vigilancia dela Administración Pública. Este control está íntimamente vinculado al anterior pues su finalidad es impedir el empleo de cláusulas ilegales o lesivas para los asegurados. La póliza es el documento que recoge el contrato de seguro, que debe constar por escrito, y debe contener una serie de requisitos mínimos establecidos por la SIBOIF. El incumplimiento a tal circunstancia acarrea consigo una sanción para el asegurador, y en ningún momento acarrea la pérdida del derecho del asegurado a reclamar la indemnización.

No entraremos en más detalles sobre el tema porque el mismo fue tratado de forma indirecta en los apartados anteriores.

\section{De los órganos de control o supervisión}

Son las instancias que se encargan de autorizar, supervisar y fiscalizar el correcto funcionamiento del sistema financiero en general, en el país. Esa función ha sido delegada por el Estado a la Superintendencia de Bancos y de Otros Instituciones Financieras (SIBOIF), quien es el actor clave del sistema financiero nacional, pues de su actuar depende que el sistema se encamine por los cauces legales y económicos permitidos, por tal razón el legislador le ha delegado funciones, facultades y atribuciones fundamentales para la protección del sistema financiero nacional. La SIBOIF es regida por la Ley No. 316 Ley de la Superintendencia de 
Bancos y de otras Instituciones Financiera y sus reformas Ley No. 552, Ley 564 y la Ley No. $576^{40}$. Según la misma Ley 316 la existencia jurídica de la SIBOIF, fue creada por la Ley No. 125 del 21 de marzo de 1990, la cual ha permanecido sin solución de continuidad desde la entrada en vigencia de la Ley No. 125.

La SIBOIF es una institución autónoma del Estado, con capacidad jurídica para adquirir derechos y contraer obligaciones respecto de aquellos actos o contratos que sean necesarios para el cumplimiento del objetivo establecido por la Ley (art. 1 Ley 316).

1. El papel de la Superintendencia de Bancos y Otras Instituciones Financieras no Bancarias (SIBOIF)

Como entidad supervisora del sistema financiero nacional en general (y en particular la de seguros), el papel fundamental de la SIBOIF está referido a sus dos funciones primordiales, que justifican su creación:

a. Velar por los intereses de los depositantes, y de los demás clientes o usuarios de las instituciones financieras y no financieras. Aplicado al ámbito de los seguros, es velar por los intereses de los asegurados que confían sus fondos (primas) a las empresas aseguradoras autorizadas para operar, y;

b. Salvaguardar el sistema financiero nacional, debido su importancia económica para el país, a través de la preservación de la seguridad y confianza del público en dichas instituciones, promoviendo una adecuada supervisión que procure su solvencia y liquidez en la intermediación de los recursos a ellas confiados.

El art. 2 de la Ley 316, le encarga la autorización, supervisión y fiscalización de la constitución y funcionamiento de todos los bancos, sucursales y agencias bancarias que operen en el país, así como de las instituciones financieras no bancarias y de los grupos financieros.

Para el cumplimiento de su papel fundamental y de sus fines, las atribuciones establecidas por ley (art. 3 Ley 316, reformado por la Ley No. 552, art. 1), de las que destacamos algunas relacionadas a los seguros:

40 La Gaceta, Diario Oficial, No. 196, del 14 de octubre de 1999. La Gaceta, Diario Oficial, No. 169, de 31 de agosto de 2005. La Gaceta, Diario Oficial, No. 228, del 24 de noviembre de 2005 y La Gaceta, Diario Oficial, No. 58, del 22 de marzo de 2006, respectivamente. 
1. Resolver las solicitudes presentadas por personas naturales o jurídicas, nacionales o extranjeras para constituir y poner en operación nuevos bancos, sucursales y agencias bancarias y demás instituciones a que se refiere el artículo anterior.

2. Supervisar, inspeccionar, vigilar y fiscalizar el funcionamiento de todas las entidades bajo su ámbito de acción.

3. Regular la suficiencia de capital, la concentración de crédito, el crédito a partes relacionadas y la clasificación y provisionamiento de cartera.

4. Hacer cumplir las leyes especiales y generales y las normas reglamentarias que rijan para la constitución, transformación, disolución y liquidación de las instituciones sujetas a su supervisión, inspección, vigilancia y fiscalización.

5. Resolver la intervención de cualquier banco o entidad financiera no bancaria, en los casos contemplados por la ley.

6. Solicitar la liquidación forzosa de cualquier banco o entidad financiera no bancaria bajo su supervisión, inspección, vigilancia, y fiscalización, en los casos contemplados por la ley, y ejecutarla cuando la ley le atribuye esa facultad.

7. Requerir de los bancos y demás instituciones supervisadas, inspeccionadas, vigiladas y fiscalizadas, los informes que necesite para el cumplimiento de sus funciones.

8. Inspeccionar regularmente las instituciones que le corresponda, vigilar y realizar arqueos y otras verificaciones convenientes por medio del personal de la Superintendencia o el debidamente contratado para tal efecto. En este caso el personal está obligado a observar el sigilo bancario, so pena de responsabilidades civiles y penales según el caso. Estas inspecciones, arqueos y verificaciones deberán realizarse por lo menos una vez al año y podrán llevarse a cabo sin previo aviso a las instituciones a inspeccionar.

9. Declarar sin valor legal y sin efectos societarios y jurídicos los nombramientos de los Directores, del Gerente General o del Principal Ejecutivo y del Auditor Interno de las Instituciones Financieras sujetas a su supervisión, inspección, vigilancia, y fiscalización, si no llenan los requisitos de ley. Así mismo, podrá ordenar la destitución de los Directores y funcionarios de las Instituciones sometidas a su competencia, por irregularidades cometidas en el ejercicio de sus funciones de conformidad con esta Ley, todo sin perjuicio de las responsabilidades civiles o penales que correspondan. 
10. Impartir a las instituciones sujetas a su supervisión, inspección, vigilancia y fiscalización, las instrucciones necesarias para subsanar las deficiencias o irregularidades que se encontraren y adoptar las medidas que sean de su competencia para sancionar administrativamente y corregir las infracciones que se hubieren cometido.

11. Dictar las normas y disposiciones necesarias para el cumplimiento del objeto de esta Ley.

La SIBOIF tendrá competencia exclusiva en el ejercicio de sus facultades legales de supervisión, inspección, vigilancia y fiscalización de las entidades a las que se refiere la Ley 316, con exclusión de cualquier otra autoridad administrativa o de control. Lo anterior, sin perjuicio de la obligación del Superintendente de informar sobre su gestión a la Asamblea Nacional.

Para el cumplimiento de sus funciones y atribuciones, la SIBOIF tiene como órganos superiores un Consejo Directivo, un Superintendente y un Vice Superintendente (art. 4 Ley No. 316). El Superintendente y el Vice Superintendente son electos por la Asamblea Nacional (art. 138 numeral 8 de la Constitución Política de Nicaragua), por un periodo de 5 años.

Por su parte el Consejo Directivo es formado por el Presidente del BCN, quien lo preside, el Superintendente de Bancos y cuatro miembros con sus suplentes nombrados por el Presidente de la República y ratificados por la Asamblea Nacional (art. 5 Ley No. 316, y su última reforma por la Ley No. 564 que entró en vigencia el 20 de enero de 2007). Mediante la Resolución No. CD-SIBOIF-490-1-JUL18-2007 del 18 de julio del año 2007, se aprueba el Reglamento Interno del Consejo Directivo de la SIBOIF, norma que sirve de base para el funcionamiento de dicho órgano.

Además de los órganos ya señalados la SIBOIF, tiene cuatro intendencias (art. 8 Ley 316):

- Intendencia de Bancos y de otras Instituciones Financieras

- Intendencia de Seguros

- Intendencia de Valores

- Intendencia de Almacenes Generales de Depósito. 
En materia de seguros el papel fundamental de fiscalización y vigilancia está regulado en los arts. 64 al 77 de la LGIS, en los cuales se le dota de las siguientes facultades para el cumplimiento de su misión, en materia de seguros:

a. Realizar visitas de inspección a las oficinas de las instituciones, de conocer y revisar la correspondencia, libros de contabilidad y los documentos que justifiquen los asientos y cuentas, de comprobar inversiones y en general, de efectuar todo lo necesario para vigilar la marcha de las operaciones (art. 64 LGIS)

b. Dictar normas de contabilidad a las instituciones de seguros, exigirles la presentación periódica de Balances de comprobación y Balances Generales y sus correspondientes anexos, Estados de Ganancias y Pérdidas Actuariales y sus anexos, Información estadística, detalles de Inversiones e informes de toda clase. Éstos se presentaran mensualmente y se publicarán trimestral y anualmente para informar al público.

c. Emitirinstrucciones relacionadas con sus facultades alas instituciones de seguros.

d. Suspender o revocar la autorización para operar, concedida a cualquiera institución de seguros, según causales establecidas en la ley.

La SIBOIF emite resoluciones dentro del ámbito de su competencia, contras las resoluciones emanadas por la SIBOIF caben los recursos administrativos. La reforma del art. 20 por la Ley No. 552 introduce significantes avances en este tema. Es así, que contra las resoluciones que emita el Superintendente cabe el Recurso de Revisión dentro del plazo de diez días hábiles a partir de la fecha de notificación. Contra esta resolución cabe el recurso de apelación, este recurso se tramita ante el Consejo Directivo, el plazo para interponer el recurso es de cinco días hábiles a partir de la notificación de la resolución de revisión. La Resolución No. CD-SIBOIF-454-1-NOV28-2006 de fecha 28 de noviembre del 2006 establece la "Norma para la tramitación de Recursos Administrativos", desarrolla más a fondo el tema.

\section{De las instituciones de protección al consumidor}

Para proteger los derechos de los consumidores, se han constituido organizaciones privadas especializadas en la defensa de los mismos, tales como: La Liga de Defensa de los Consumidores de Nicaragua 
(LIDECONIC), La Red Nacional de Defensa delos Consumidores(RNDC), Centro de Promoción y Protección de los Derechos de Consumidores y Usuarios de Nicaragua (CEPRODUC).

Instituciones constituidas como personas jurídicas sin fines de lucro al amparo de la Ley No. 147 Ley General sobre Personas Jurídicas sin Fines de Lucro, publicada en La Gaceta, Diario Oficial No.102 de 29 de Mayo de 1992. Comparten un objetivo común que es informar a las instancias correspondientes lo problemas que afectan a los consumidores y usuarios, sobre todo los relacionado con precios, calidad y cláusulas abusivas, además de proponer iniciativas de ley y reformas para la protección y mejoramiento de los derechos de los consumidores.

En la actualidad existen alrededor de 11 asociaciones de protección a los consumidores y usuarios, la mayoría en Managua, pero también en departamentos como León, Masaya, Granada, Chinandega y la Isla de Ometepe.

Ninguna de las asociaciones se especializa en la protección de los consumidores de servicios financieros, tampoco han realizado sugerencias para mejorar la situación actual y proponer mejoras en la regulación pertinente al tema, a diferencia de lo que sucede en México donde existe la Comisión Nacional para la Protección y Defensa de los Usuarios de Servicios Financieros, entidad creada únicamente para asesorar y atender los reclamos de los usuarios de los diversos servicios financieros. Dicho organismo está amparado en la Ley de Protección y Defensa al Usuario de Servicios Financieros, Publicada en el Diario Oficial de la Federación el 18 de enero de 1999, en el cual se establece una comisión que es la encargada de atender todos los reclamos, dicha comisión está formada por los representante de todos los actores involucrados en el tema.

Otros países como España y Argentina, tienen la figura del Defensor Asegurado (Ombudsman), que es una persona designada por la entidad de seguros o un grupo de entidades aseguradoras, a fin de que resuelva los reclamos que se deduzcan de los asegurados o beneficiarios, contra la resoluciones de las entidades de seguros que fueren adversa. De esta forma se evita aumentar el trabajo del ente supervisor y se da una respuesta rápida, que beneficia a todos los involucrados. 


\section{Instituciones Internacionales de supervisores de seguros}

Como señalamos en apartados anteriores en América Latina, se destaca el papel de la Asociación de Supervisores de Seguros de América Latina, ASSAL.

La ASSAL agrupa a las máximas autoridades supervisoras de la actividad de seguros de Latinoamérica. En el apartado de los PBS se detalló la información de su organización.

Dentro de los objetivos de ASSAL se destacan

1. Intercambiar información sobre legislación, métodos de control, características de mercado y sistemas operativos en cada uno de los países en materias de seguros y reaseguros.

2. Recolectar y difundir información técnica y estadística.

3. Promover las actividades de cooperación.

4. Analizar el desenvolvimiento del reaseguro en la región.

5. Incentivar programas regionales en materia de educación de seguros y reaseguros.

6. Armonizar las políticas y mecanismos de supervisión.

7. Transmitir las experiencias registradas en los países miembros respecto a temas específicos de la industria aseguradora.

Estas instituciones contribuyen a unificar los criterios de supervisión en la región y en el mundo entero, de tal forma que la misma se haga más fácil y uniforme en los países miembros de las asociaciones.

A nivel internacional destaca la IAIS, International Association of Insurance Supervisors. Creada en 1994, sus socios son entidades supervisoras de seguros de alrededor de 190 jurisdicciones distintas y cuenta con observadores en alrededor de 120 países. Nicaragua no es miembro de IAIS, tiene los mismos objetivos de ASSAL pero con una proyección internacional.

A nivel internacional es la de mayor proyección y de mayor peso.

\section{Otros actores claves}

La supervisión recae sobre las empresas de seguros constituidas legalmente y autorizadas para operar en el país, en este sentido son ellos los destinatarios finales de la supervisión; pero no son los únicos. 
También son destinatarios finales de la supervisión los Intermediares de Seguros, tales como, los corredores, las agencias y los agentes de seguros, ya que su función consiste en la realización de la intermediación para la asesoría, la contratación y renovación de seguros.

Los intermediarios operan bajo la supervisión de la SIBOIF y deben estar autorizados por dicha entidad para poder operar en el país y contar con una licencia expedida por la misma institución, dicha autorización o licencia, según el caso es garantizada con una fianza o cualquier garantía fijada por la SIBOIF. La regulación de los intermediarios la encontramos en los arts. 78 a 84 de la LGIS.

\section{Conclusiones}

1. Las disposiciones relacionadas con seguros se encuentran dispersas en diferentes cuerpos normativos, como el Código Civil, Código de Comercio, LGIS. Es necesario unificar criterios y consolidar la regulación sobre la materia, ya que eso facilitaría la revisión y control ejercida por la SIBOIF en el ámbito del contenido de los contratos y de las pólizas de seguros.

2. El sistema de supervisión se focaliza en la capacidad financiera de las empresas de seguros, orientados en velar porque dichas empresas puedan pagar sus compromisos derivados de la venta de seguros, para ello pone relevancia en aspectos como las Reservas Técnicas y Matemáticas, Capital Social Mínimo y de Riesgo, Régimen de Inversiones, Estado de Solvencia, entre otros. En consecuencia, la supervisión se ha centrado en la verificación del cumplimiento de la regulación de solvencia y en la auditoria de estados financieros e información anexa, así como en la prevención del lavado de dinero, destinada a que se refleje adecuadamente la situación de la compañía.

3. La SIBOIF carece de un modelo de supervisión como han adoptado otros países como México y Chile. En consecuencia, se limita y se concentra en la supervisión financiera, como se plantea en el punto anterior, dejando al margen otros aspectos que también son fundamentales en la supervisión y limitándose a cumplir con requerimientos normativos de Organismos Internacionales, incorporándolos a nuestro ordenamiento jurídico a través de las Normas Técnicas.

4. Se carece de los mecanismos eficaces para que los asegurados puedan presentar sus reclamos ante la SIBOIF, no existe un procedimiento como tal, escasamente contamos con algunos artículos que regulan 
la materia y una NT relacionada al procedimiento administrativo ante esta instancia. El Superintendente carece de facultades amplias y suficientes para resolver asuntos de esta naturaleza. No se utilizan los MARC, como formas económicas y eficientes para resolver las controversias.

\section{Recomendaciones}

1. Aprovechar el proyecto de LGISR, para incluir lo relacionado a la regulación del Seguros (referente a los aspectos sustantivos el Contrato de Seguro) y unificar en un solo texto las disposiciones relacionadas, tanto a aspectos contractuales, de organización, operación y supervisión.

2. Crear un modelo de supervisión, que siente las bases para un sistema de regulación por auto supervisión. En este nuevo esquema, deberán existir organismos de gobierno como un Consejo de Administración, un Comité de Auditoría Interna, un Comité de Riesgos y en algunos casos un Comité de Prácticas Societarias. Estos organismos generan un contrapeso a la Dirección para la toma de decisiones y ayudan a que la SIBOIF, pueda ejercer un control más ordenado y de cara a un objetivo previamente establecido. No seguir dictando normativa técnica, únicamente por cumplir con lineamientos internacionales, sin saber hacia dónde vamos y cuál es el objetivo primordial de ello.

3. Adoptar un modelo de supervisión, tal como se establece en el proyecto LGISR. Este modelo será la Supervisión Basada en Riesgo, para ello debe generar los mecanismos de implementación idóneos y necesarios para la consecución del objetivo final, la sanidad del sistema financiero nacional y la protección de los asegurados.

4. Crear un proceso de reclamo en dos sentidos, en primer lugar, unificar los manuales de reclamos de las aseguradoras y qué estos sean del conocimiento del público en general, que contenga como mínimo los pasos a seguir para presentar un reclamo, y, en segundo lugar crear un proceso administrativo en el que se establezca y garantice el debido proceso, la transparencia y publicidad de todas las partes. Ello implica dotar de facultades legales y recursos económicos a la SIBOIF para atender las solicitudes de reclamos, lo que sin duda implicará la creación de una oficina especial para tal fin. Estos cambios, pueden incluirse en el Proyecto LGISR.

5. La SIBOIF podría proponer, a través de instrucciones o NT el uso de los MARC para resolver las controversias que surjan entre asegurador y asegurado. 
6. Hacer pública las facultades con las que cuenta actualmente la SIBOIF, en materia de atención de reclamos de los asegurados, porque existe gran desconocimiento en el tema y un alto índice de insatisfacción hacia el papel que ejerce.

\section{Lista de referencias}

Argüello Ramírez, L. (2007). Aspectos Institucionales del Mercado de Seguros: Autoridad de Supervisión. El Estatuto de las Entidades Aseguradoras y el Régimen Jurídico del Mercado de Seguros. Módulo autoformativo de la Maestría en Derecho de Empresa, Especialización en Derecho del Mercado Financiero, No. 7. Managua: Facultad de Ciencias Jurídicas.

Bullo, E. H.(1999). El Derecho de Seguros y de otros negocios vinculados. Tomo I, El Contrato de Seguro en General. Buenos Aires: Editorial Abaco de Rodolfo Depalma.

Bullo, E. H. (1999). El Derecho de Seguros y de otros negocios vinculados. Tomo III, La Regulación en las empresas de seguros. Buenos Aires: Editorial Abaco de Rodolfo Depalma.

Guzmán, J. Herrera, J. (2009). Contratos Civiles y Mercantiles: Contrato de Seguros. ( $2^{\text {a }}$ ed.). Managua: Facultad de Ciencias Jurídicas, UCA.

Habed Blandón, V. (2007). Seguros: compendio y análisis de leyes $y$ disposiciones del seguro privado en Nicaragua. ( $2^{\mathrm{a}}$. ed.). Managua: Litografía Marcel.

Herrera Espinoza, J. (2008). Derecho Bancario; doctrina y legislación. $\left(2^{\mathrm{a}}\right.$. ed.). Managua: UCA.

Instituto de la Ciencia del Seguro. Fundación MAPFRE. (2008). Temas Relevantes del Derecho de Seguros Contemporáneo. Madrid: Fundación MAPFRE.

Leiva Fernández, L. (2009). Introducción al Derecho de Seguros. Managua: Facultad de Ciencias Jurídicas. 
Macías Muñoz, O. \& Pérez Jiménez, F. (2008). Tema I. Fiscalización de la actividad aseguradora (17-74). En Instituto de la Ciencia del Seguro. Fundación MAPFRE. Temas Relevantes del Derecho de Seguros Contemporáneo. Madrid: Fundación MAPFRE.

Robleto Arana, C. (2007). Compendio de jurisprudencia nacional y extranjera de seguros. Managua.

Robleto Arana, C. (2007). Contratos de seguros: doctrina y jurisprudencia. Managua: UCA.

Sánchez Calero, F. (2002). Instituciones de Derecho Mercantil. Volumen II. (24 ed.). Madrid: Mc Graw Hill.

Schiavo, C. (2008). Tema VI. La Defensa del Asegurador: Justicia Ordinaria, Arbitraje, Mediación y Defensor del Asegurado: La Mediación y la Defensa del Asegurado. En Instituto de la Ciencia del Seguro. Fundación MAPFRE. Temas Relevantes del Derecho de Seguros Contemporáneo (451-467). Madrid: Fundación MAPFRE.

Soto, H. (2008). Tema VI. La Defensa del Asegurador: Justicia Ordinaria, Arbitraje, Mediación y Defensor del Asegurado: El Defensor del Asegurado. En Instituto de la Ciencia del Seguro. Fundación MAPFRE. Temas Relevantes del Derecho de Seguros Contemporáneo (467-489). Madrid: Fundación MAPFRE.

Stiglitz, R. (2008). Derecho de Seguros. Volumen I. (5ª ed.). Buenos Aires: La Ley.

\section{Legislación}

Código Civil de la República de Nicaragua. 1904.

Código de Comercio de la República de Nicaragua. 1914.

Decreto No 1727, “Ley General de Instituciones de Seguros”, publicada en La Gaceta, Diario Oficial, No. 270, del 26 de noviembre de 1970.

Ley No. 182, Ley de Defensa de los Consumidores, publicada en La Gaceta, Diario Oficial No. 213 del 14 de noviembre de 1994. 
Ley No. 227, Ley de Reforma a la Ley General de Instituciones de Seguros, publicada en La Gaceta, Diario Oficial, No. 150 del 12 de agosto de 1996.

Ley No. 316, Ley de la Superintendencia de Bancos y de Otras Instituciones Financieras, publicada en La Gaceta, Diario Oficial No. 196 del 14 de octubre de 1999.

Ley No. 564, Ley de Reforma a la Ley 316, Ley de la Superintendencia de Bancos y Otras Instituciones Financieras, publicada en La Gaceta, Diario Oficial No. 228 del 24 de noviembre de 2005.

Ley No. 576, Ley de Reforma a la Ley 316, Ley de la Superintendencia de Bancos y Otras Instituciones Financieras, publicada en La Gaceta, Diario Oficial No. 58 del 22 de marzo de 2006.

Proyecto Ley de Protección a los Derechos de los Consumidores y Usuarios.

Proyecto Ley General de Instituciones de Seguros, Reaseguros y Fianzas.

\section{Normas técnicas}

Resolución No. CD-SIBOIF-536-1-JUN4-2008 "Norma sobre Contenido Mínimo del Código de Conducta para Directores, Gerentes, Auditores Internos y Empleados", publicada en La Gaceta, Diario Oficial No 124 del 01 julio de 2008.

Resolución No.CD-SIBOIF-465-3-FEB7-2007 "Norma sobre Manual Unico de Cuentas para Compañías de Seguros, Reaseguros y Afianzadoras”, publicada en La Gaceta, Diario Oficial No 69 del 13 de abril de 2007.

Resolución No. CD-SIBOIF-596-1-SEP9-2009, "Norma sobre Controly Auditoría Interna”, publicada en La Gaceta, Diario Oficial No. 203 del 27 de octubre de 2009.

Resolución No. CD-SIBOIF-611-3-ENE22-2010, "Norma de Actualización del Capital Social de las Compañías de Seguros", publicada en el El Nuevo Diario del o1 de febrero de 2010. 
Resolución No. CD-SIBOIF-597-3-SEP23-2009 Norma sobre Requisitos para ser Director, Gerente General y/o Ejecutivo Principal y Auditor Interno de Instituciones Financieras, publicada en La Gaceta, Diario Oficial No. 210 y 214, del 05 y 11 de noviembre de 2009.

Resolución No. CD-SIBOIF-428-1-JUN27-2006 Norma sobre Límites de Inversión de Instituciones de Seguros y Reaseguros, publicada en La Gaceta, Diario Oficial No 141 del 21 de julio de 2006.

Resolución No. CD-SIBOIF-454-1-NOV28-2006 Norma para la Tramitación de Recursos Administrativos, publicada en La Gaceta, Diario Oficial $\mathrm{N}^{\mathrm{O}} 24$ del 02 de febrero de 2007.

Resolución No. CD-SIBOIF-583-2-ABR29-2009, Norma sobre Auditoría Externa, publicada en La Gaceta, Diario Oficial No 99 del 29 de mayo de 2009.

\section{Consultas en línea}

Asociación Internacional de Supervisores de Seguros. Acerca de Assal. Recuperado el 12 de abril de 2010, de http://www.assalweb.org/ que_es_assal.php?random $=911$.

Banco Central de Nicaragua. Información General. Recuperado el día 14 de abril de 2010, de http://www.bcn.gob.ni/banco/index. html?\&val=o\#.

Comisión Nacional de Bancos y Seguros de Honduras. Principios Básicos de Seguros. Recuperado el 12 de abril de 2010, de http://www. cnbs.gov.hn/web/index.htm.

Comisión Nacional para la Protección y Defensa de los Usuarios de Servicios Financieros. Origen de la actividad aseguradora en México. Recuperado el día 12 de abril de 2010, de http://www. condusef.gob.mx/index.php/item-3/794.html.

International Association of Insurance Supervisors (2010). About IAIS. Recuperado el día 21 de abril de 2010, de http://www.iaisweb.org/ index.cfm?pageID=28 
Superintendencia de Bancos y de Otras Instituciones Financieras. Reseña Histórica delSeguro. Recuperado el 12 de abril de 2010 http://www. superintendencia.gob.ni/index.php?cont $=$ temp\&id $=8 \&$ seccion $=3$.

Superintendencia de Seguros y Reaseguros de Panamá (2010). Reseña Histórica. Recuperado el día 21 de abril de 2010, de http://www. superseguros.gob.pa/.

Veiga Copo, A. (2007). Derecho de Seguros en la Unión Europea: La Dimensión Pública de la Actividad Aseguradora. La Supervisión y El Control. Recuperado el día 10 de enero de 2010, de http:// portales.gva.es/c_economia/web/rveh/pdfs/n14/o4_observa2.pdf

\section{Abreviaturas}

ASSAL: Asociación Internacional de Supervisores de Seguros.

BCN: Banco Central de Nicaragua.

C: $\quad$ Código Civil de Nicaragua.

Ce: $\quad$ Código de Comercio de Nicaragua.

Cn: Constitución Política de Nicaragua.

EL CONSEJO: Consejo Directivo de la SIBOIF.

INISER: Instituto Nicaragüense de Seguros y Reaseguros.

LDC: $\quad$ Ley de Defensa del Consumidor.

LGBIOF: Ley General de Bancos y de Otras Instituciones Financieras no Bancarias y Grupos Financieros

LGIS: Ley General de Instituciones de Seguros.

MARC: Métodos Alternos de Resolución de Controversias.

NT: $\quad$ Normas Técnicas emitidas por la SIBOIF

PBS: $\quad$ Principios Básicos de Seguros.

PLD/FT: Prevención del Lavado de Dinero y Financiamiento al Terrorismo.

PROYECTO DE LGISR: Proyecto de Ley General de Seguros, Reaseguros y Fianzas.

PROYECTO DE LPDCU: Proyecto Ley de Protección a los Derechos de los Consumidores y Usuarios.

REFORMA DE LGIS: Ley No 227, Ley de Reforma a la Ley General de Instituciones de Seguros y Reaseguros.

SBR: $\quad$ Supervisión Basado en Riesgos

SIBOIF: Superintendencia de Bancos y de Otras Instituciones Financieras. 